\title{
Wirtschaften im Umbruch : Ordnung, Unternehmer und Stil
}

\author{
Citation for published version (APA):
}

Backhaus, J. G. (1997). Wirtschaften im Umbruch : Ordnung, Unternehmer und Stil. METEOR, Maastricht University School of Business and Economics. METEOR Research Memorandum No. 012 https://doi.org/10.26481/umamet.1997012

Document status and date:

Published: 01/01/1997

DOI:

10.26481/umamet.1997012

Document Version:

Publisher's PDF, also known as Version of record

\section{Please check the document version of this publication:}

- A submitted manuscript is the version of the article upon submission and before peer-review. There can be important differences between the submitted version and the official published version of record.

People interested in the research are advised to contact the author for the final version of the publication, or visit the DOI to the publisher's website.

- The final author version and the galley proof are versions of the publication after peer review.

- The final published version features the final layout of the paper including the volume, issue and page numbers.

Link to publication

\footnotetext{
General rights rights.

- You may freely distribute the URL identifying the publication in the public portal. please follow below link for the End User Agreement:

www.umlib.nl/taverne-license

Take down policy

If you believe that this document breaches copyright please contact us at:

repository@maastrichtuniversity.nl

providing details and we will investigate your claim.
}

Copyright and moral rights for the publications made accessible in the public portal are retained by the authors and/or other copyright owners and it is a condition of accessing publications that users recognise and abide by the legal requirements associated with these

- Users may download and print one copy of any publication from the public portal for the purpose of private study or research.

- You may not further distribute the material or use it for any profit-making activity or commercial gain

If the publication is distributed under the terms of Article $25 \mathrm{fa}$ of the Dutch Copyright Act, indicated by the "Taverne" license above, 
Revised, 19 March 1997

\section{WIRTSCHAFTEN IM UMBRUCH: ORDNUNG, UNTERNEHMER UND STIL}

Zur Veröffentlichung in: Ordnungskonforme Wirtschaftspolitik in der Marktwirtschaft: Festschrift für H.-R. Peters. Berlin: Duncker \& Humblot, 1997.

Prof. Dr. Jürgen G. Backhaus

Universität Maastricht (AE)

Postfach 616

NL-6200 MD Maastricht

Die Niederlande

tel: $+31-43-3883652 / 3636$

fax: +31-43-3258440

email: f.schijlen@algec.unimaas.nl (f.schijlen@algec.rulimburg.nl) 


\begin{abstract}
The purpose of this article is to explore the usefulness of these concepts in economic theory: (1) order; (2) entrepreneur; and (3) style for modern analysis. Obviously, all three categories require primarily qualitative data for explanation built around them. In this essay, the major area of application is the theory of economic policy, notably when economic and social transitions loom large.
\end{abstract}

J.E.L. code: B25, P27, P35 


\title{
WIRTSCHAFTEN IM UMBRUCH: ORDNUNG, UNTERNEHMER UND STIL ${ }^{1}$
}

\author{
I Von der Anteils - zur Kontrollwirtschaft \\ II Ordnung in der politisch-ökonomischen Theorie \\ III Der Unternehmer in der ökonomischen Theorie \\ IV Kombination und Informationsübertragung: Eine verfahrenstheoretische Interpretation \\ V Gleichgewicht und Wohlfahrt \\ VI Politische Unternehmer \\ VII Der Wirtschaftsstil \\ VIII Der neue Osten \\ IX Ordnung, Unternehmer und Stil \\ X Nutzen und Anwendungsmöglichkeiten einer ökonomischen Theorie der politischen \\ Unternehmer und der Wirtschaftsstile im Hinblick auf die Probleme der \\ Transformationsökonomie
}

\section{EINLEITUNG}

Dieser Essay beschäftigt sich mit Transformation und Innovation in östlichen Wirtschaften, also den sogenannten Transformationsökonomien. Der Schwerpunkt liegt auf der Betonung von Strukturen und Wirtschaftsformen, die den uns bekannten unähnlich sind. Um diese Unterschiede herauszuarbeiten, wird auf drei traditionelle Konzepte in den Wirtschaftswissenschaften zurückgegriffen, die Ordnung, den Unternehmer und den Wirtschaftsstil. Es handelt sich in allen drei Fällen um heute ungebräuchliche Konzepte, die jedoch, so der Tenor des Essays, die östlichen Volkswirtschaften in ihrem Umbruch sehr viel besser verständlich machen. Das verwendete empirische Material beruht auf einer umfänglichen Auswertung der internationalen Wirtschaftspresse.

\section{VON DER ANTEILS - ZUR KONTROLLWIRTSCHAFT}

Die Wirtschaften in Zentral- und Osteuropas, die sich nach der Welle der Revolutionen von 1989 im Umbruch befinden, stellen den Volkswirt immer wieder vor Rätsel. Wer den Statistiken Glauben schenken möchte, kann sich nur wundern, warum trotz hoher Arbeitslosigkeit und Produktionseinbrüchen dennoch von Hungersnöten, Seuchen, Massenkrawallen und einer allgemeinen politischen Radikalisierung, alles Zeichen tiefer wirtschaftlicher Krisen, kaum die Rede ist. Wo die Staatswirtschaft abbröckelt, aber die Marktwirtschaft noch nicht besteht, wird dennoch

1 Das in diesem Aufsatz ausgebreitete Gedankengut entspringt vor allem langen Diskussionen mit Richard E. Wagner (George Mason University). Die Arbeit wurde anläßlich der Sitzung des Ausschusses zum Vergleich von Wirtschaftssystemen des Vereins für Socialpolitik vom 25. bis 27. September 1994 in Jena ausführlich diskutiert. Insbesondere danke ich den Herren Kollegen Cassel, Engelhardt, Klinkmüller, Schüller, Tuchtfeldt und Wagner für wertvolle Hinweise und Kritik. 
gewirtschaftet. $^{2}$ Es gibt Anzeichen unternehmerischer Initiative, und es gibt Anzeichen von Kapitalbildung, obwohl Finanz- und Kapitalmärkte weitgehend fehlen. In diesem Aufsatz wird versucht, den vielfältigen Strukturen gerecht zu werden, die uns in der internationalen Wirtschaftspresse, die über die östlichen Wirtschaften im Umbruch berichtet, dargestellt werden, die sich aber nicht gut in das Schema von Markt- und Planwirtschaft einfügen lassen. Wenn wir das Wirtschaftsgeschehen nicht in unsere Denkvorstellungen oder "Modelle" einfügen können, können wir uns kaum eine Vorstellung davon machen, wie diese Wirtschaften heute funktionieren und wie sie eventuell morgen aussehen könnten. Um die Modellwelt anzureichern, greife ich auf drei klassische heute aber weitgehend vergessene analytische Kategorien zurück: den Unternehmer und den Wirtschaftsstil; daneben steht das Konzept der Ordnung das im Werk des Jubilars den zentralen Platz einnimmt.

Die wirtschaftsanalytischen Probleme, die die Entwicklung der neuen östlichen Wirtschaften aufwirft, sind nicht auf diese begrenzt. Auch die Unterschiede zwischen westlichen Wirtschaften lassen sich nicht in das Schema Marktwirtschaft - Planwirtschaft pressen. Zum Beispiel beginnt die Wirtschaftsjournalistin Judith Balenty ihren Vergleich zwischen Großbrittanien und Italien mit den folgenden Worten:

"The European Union dreams of the day its sorted nations will be joined into one big, happy national market. However, differences in national personalities and economic characteristics make it unlikely that a single model can apply to all.

Britain and Italy - two countries of nearly equal population - provide one of the starkest contrasts. Britain has followed a text book free market model. It sold nationalised companies to the private sector, slashed the government jobs and phased out loss producing industries, particularly in the coal and steel sectors.

Italy, on the other hand, remains top heavy with state supported industries. Plagued by political scandals, it has yet to take some of the difficult economic steps that Britain did. Yet neither country can be characterized as better off than the other, because each has continuing - and quite different - home grown economic problems to solve." 3

Die Autorin führt ferner aus, inwiefern sich die beiden europäischen Mitgliedsländer unterscheiden, nicht nur im Hinblick auf das Ausmaß des erwerbstätigen öffentlichen Sektors, sondern im Hinblick auf das Sparverhalten der Bevölkerung, die Existenz mittelständischer Betriebe und so weiter. Was umständlich mit nationalen Persönlichkeiten und wirtschaftlichen Charakteristiken umschrieben wird, errinnert an das alte Konzept des Wirtschaftsstils, welches feiner gefächert als das Konzept des Wirtschaftssystems eine genauere wirtschaftsvergleichende Analyse möglich machen sollte.

2 Für Deutschland vgl. literarisch den Beitrag von Siegfried Lenz, Lehmanns Erzählungen oder So schön war mein Markt. Hamburg: Hoffmann und Camper, 1964 (= München: deutscher taschenbuchverlag)

Judith Balenty, "Two paths, two problems: neither a free market nor broad state ownership alone garantee success. Ask Britain and Italy." Wall Street Journal Europe, Monday, October 3, 1983, R8. 
Die zentral- und osteuropäischen Wirtschaften, auf die hier das Stilkonzept angewendet wird, werden oft als Transformationsökonomien bezeichnet. Dahinter steht "implizit oder explizit" die Vorstellung, diese Wirtschaften machten einen Transformationsprozeß von der Planwirtschaft zur Marktwirtschaft mit. Tatsächlich wissen wir nur, daß sich diese Wirtschaften im Umbruch befinden, keineswegs aber in welche Richtung hin sie sich entwickeln. Es ist keineswegs sicher, daß alle östlichen Wirtschaften sich dem anglo-amerikanischen Marktmodell fügen werden, ebensowenig, wie die westeuropäischen Wirtschaften demselben Modell folgen. Deshalb wird im folgenden konsistent von "Wirtschaften im Umbruch" gesprochen, und zwar mit dem geographischen Attribut "östlich", um deutlich zu machen, um welche Wirtschaften es sich handelt und auch, daß der Aspekt des Systemwandels im Vordergrund steht, nicht jener der wirtschaftlichen Entwicklung. ${ }^{4}$

In den letzten Jahren läßt sich in den entwickelten Demokratien westlicher Prägung ein eigenartiges Phänomen beobachten. Durchaus im Gegensatz zu den damals vielbeachteten Ausführungen John Kenneth Galbraiths, der 1958 in seinem "The Affluent Society" überschriebenen Buche beredte Klage über das parallele Auftreten privaten Reichtums und öffentlicher Armut führte, läßt sich ein Sinken der Wachstumsraten in den genannten Volkswirtschaften bei gleichzeitigem, zum Teil atemberaubendem Anstieg der Staatsquote beobachten. (Rühle \& Veen (1979)) Einerseits sieht sich die Privatwirtschaft einer steigenden Belastung durch sowohl klassische Besteuerung in direkter wie indirekter Form als auch durch in stets neuen Variationen und kumulativ auftretende administrative und politische Steuerung ausgesetzt. Dies führt dazu, daß, obwohl in einigen Bereichen die Gewinnlage der privaten Wirtschaft durchaus gut bis exzellent ist, allgemein die Aussicht niedriger Wachstumraten nicht mehr alarmierend wirkt. Wenn ein großer Teil der Bevölkerung ernsthaft "Nullwachstum" erwägt oder sogar propagiert, dann bezieht sich dies stets auf den privaten Sektor. Was immer mit diesem Begriff im einzelnen gemeint sein mag, so steht doch dahinter die Vorstellung, die Rationalität der Marktprozesse finde ihre Grenze dort, wo übergeordnete Erwägungen einer anderen, politischen Rationalität folgend, neue Ziele weisen, neue Formen der sozialen Entscheidungsfindung verlangen und neue Regeln für das Wechselspiel zwischen Wirtschaft und Politik nötig erscheinen lassen.

Derartige übergeordnete Erwägungen zeigten sich natürlich besonders im Rahmen des politischen Einigungsprozesses der beiden deutschen Staaten, etwa bei der Art und Weise, wie Eigentumsund Währungsfragen entschieden wurden. Auch in den anderen Transformationsökonomien steht der wirtschaftliche und strukturelle Wandel unter einem politischen Primat, da andererseits sein Ablauf nicht gewährleistet sein könnte.

Die entsprechende Diskussion in der östlichen Literatur hat einen anderen Schwerpunkt, ist aber gleichwohl vergleichbar.

Schon vor dem zweiten Weltkriege hatte Fritz Karl Mann davon gesprochen, der Anteilsstaat (oder, wie sich Schumpeter ausdrückte, der Steuerstaat) habe sich zum Kontrollstaat gewandelt. Die hinter dieser Entwicklung liegende Tendenz einer Strukturveränderung , begleitet von einer

$4 \quad$ In diesem Zusammenhang ist bemerkenswert, daß Richard Portes zufolge sich die Wirtschaftsberatung der östlichen Regierungen durch die westliche Wirtschaftsberatung im wesentlichen an der amerikanischen Erfahrung orientiert. Vergleiche Richard Portes, "Integrating in the East: Lessons from German and the European Experience". Jahrestagung 1994, der Gesellschaft für Wirtschaft- und Sozialwissenschaften - Verein für Socialpolitik: Wettbewerbsfähigkeit in der ostdeutschen Wirtschaft - Ausgangslage, Handlungserfordernisse, Perspektiven. Jena 28. bis 30. September 1994. 
Veränderung der legitimatorischen Gewichte des politischen Prozesses einerseits, des Marktgeschehens andererseits, paßt präziser als das Schlagwort vom "Nullwachstum", da es nicht um "das Ende des Wachstums" der Potentiale zur Bedürfnisbefriedigung allgemein geht, sondern um eine Verschiebung der Gewichte zwischen Markt und Politik. Denn, und dies erscheint nur als Kehrseite derselben Sache, öffentliche Organisationen wachsen und blühen in zum Teil barocker Fülle. Die eingangs zitierte Einschätzung Galbraiths mag faktisch widerlegt sein. Sie spiegelt aber eine andere Einschätzung über die richtige Verteilung der Gewichte zwischen Wirtschaft und Politik wider, die zum Teil sicherlich auch die breite Zustimmung erklärt, die der Autor insbesondere außerhalb seiner Disziplin, den Wirtschaftswissenschaften gefunden hat. ${ }^{5}$

Selbst im Hinblick auf eine wirtschaftswissenschaftliche Analyse der hier nur skizzenhaft und impressionistisch umrissenen Strukturveränderung ist zunächst festzuhalten, daß sie keineswegs ein Schrumpfen des traditionellen Gegenstandes der Wirtschaftswissenschaft, das heißt der Analyse wirtschaftlicher Prozesse bedeuten kann. Wirtschaftliche Prozesse sind ja solche, die Allokation und Verteilung von Gütern, also Waren und Dienstleistungen im weitesten Sinne, bewältigen. Keineswegs werden heute seltener Entscheidungen über Allokation und Verteilung einer zudem auch nicht geminderten Anzahl ökonomischer Güter getroffen. Im Gegenteil! Die Veränderung liegt lediglich in den Verfahren, durch die diese Entscheidungsprozesse geregelt sind. Wo früher die Verteilung der Einkommen (und Vermögen) sich als gleichsam natürliche Folge des Marktgeschehens bei als legitimiert angesehenen (oder doch wenigsten akzeptierten) Ausgangspositionen ergab, lenkt heute der Sozialstaat dieselben Verteilungsprozesse mit großem Aufwand. Verwaltungsentscheidungen mehr noch als Marktentscheidungen, lenken die Allokation von Waren und Leistungen. Baugenehmigungen, die Festlegung kassenärztlicher Gebührensätze, Genehmigungen von Versicherungsprämiensstaffeln, Agrarmarktordnungen und Stützungspreise, Mindestreserven und Diskontsätze so wie die vielfältigen Auflagen und Regelungen, etwa auf dem Bereich des Wohnungswesens, die den volkswirtschaftlichen Umbruch in den östlichen Wirtschaften begleiten, sind nur einige zufällig herausgegriffene Beispiele.

Der Maastrichter Vertrag hat diese Tendenz noch verstärkt. "Marktversagen" wird von den Autoren des Vertrages und den ihn tragenden Politikern auch als Versagen der Politik zugerechnet. Diese Überzeugung wirkt stark und stilprägend. Nicht nur die drastischen Haushaltsmaßnahmen in allen Mitgliedstaaten, die der europäischen Währungsunion beitreten wollen, sondern auch die weniger oft und offen besprochenen Verfassungsänderungen, vor allem auf dem Gebiet der Wirtschafts- und Haushaltsverfassung, wirken stilveränderend.

Das Werk unseres Jubilars deutet diese Aspekte häufig an, vertieft sie aber mangels lehrbuchmäßig darstellbarer aktueller Literatur nur gelegentlich.

Aus dieser theoretischen und empirischen Sicht ergibt sich als Folgerung für die Strategie der ökonomischen Analyse, daß sich der Analytiker neuartigen Anforderungen stellen muß. Wenn weiterhin die Entscheidungsprozesse über Allokation und Verteilung Gegenstand der ökonomischen Theorie bleiben sollen, so muß sich diese Theorie nunmehr mit politischen und administrativen Prozessen vermehrt beschäftigen. Mehr noch: Die Verschiebung von marktlichen zu politischen Prozessen der Allokation und Verteilung rechtfertigt nicht nur eine vermehrte,

Vgl. besonders markant die Kritik bei Gäfgen (1974), Hayek (1967), und Monissen (1975). 
vielmehr sogar eine schwerpunktmäßige Beschäftigung mit diesen im Vergleich zu den Marktprozessen noch relativ unerforschten politischen Abläufen und Koordinationsverfahren. Wenn mehr als die Hälfte des Sozialproduktes in politischen Verfahren alloziert und verteilt wird, dann darf die ökonomische Analyse dieser politischen Prozesse nicht ein Nebengebiet der Volkswirtschaftslehre bleiben, das Beachtung allenfalls in modischen Zyklen verdient ${ }^{6}$. Die wirtschaftliche Strukturverschiebung aus dem privaten in den öffentlichen Bereich, dies können wir resümierend festhalten, stellt neue Anforderungen an die Wirtschaftswissenschaften. Betraf dies Relevanz und Gegenstand dieses Aufsatzes, so bedarf auch die Methode eines Wortes vorab:

Eine wirtschaftstheoretische Beurteilung und Bewertung dieser Strukturverschiebungen und Umbrïche ist vorab durchaus nicht möglich. Fraglos läßt sich im Rahmen einer Partialbetrachtung Funktionsversagen der Verwaltung einer alternativen Marktlösung gegenüberstellen und wohlfahrtstheoretisch bewerten. Dasselbe gilt für den umgekehrten Fall, in dem Marktversagen durch bestimmte politische Verfahren gegebenenfalls geheilt werden kann. Der Schritt von der Partialanalyse zur Totalanalyse aber eröffnet die Möglichkeit, daß sich normativ die Vorzeichen ändern. Ähnliches ist aus der second best-Analyse in der Ökonomie seit langem bekannt. Im vorliegenden Fall bedarf es dann eines Strukturvergleiches, der mit dem anerkanntesten Kriterium der Wohlfahrtstheorie, dem Paretoprinzip nur bedingt möglich ist (Backhaus 1978, III). Auf dieser Ebene erscheint lediglich die Formulierung bestimmter Anforderungen an die Verfassung einer Wirtschafts- und Gesellschaftsordnung als das äußerste, das mit den Mitteln der volkswirtschaftlichen Wohlfahrtstheorie geleistet werden kann? ${ }^{7}$.

Gegen eine voreilige Bewertung des wirtschaftlich-sozialen Strukturwandels spricht jedoch noch eine zweite Erwägung. Jener Strukturwandel läßt sich einigermaßen gleichförmig in allen entwickelten Demokratien mit Markt- oder Staatswirtschaften beobachten, und zwar je ausgeprägter, desto älter und ungebrochener die demokratische Verfassung (Olson 1978 mit umfangreichen Berechnungen). Es handelt sich also nicht um einen oktroiierten Wandel, sondern um einen eigenständig ablaufenden historischen Prozeß. Über die Bestimmungsgründe dieses Prozesses verfügen wir soweit ersichtlich nur über Vermutungen, die stark von den bisherigen wirtschaftstheoretischen Auffassungen geprägt sind. Wenn etwa Olson die auffällig niedrigen Wachstumsraten der "reifen" Demokratien mit den akkumulierten Langzeitwirkungen

$6 \quad$ Entsprechendes dürfte, wie mir scheint, auch für die Betriebswirtschaftslehre zutreffen. Nicht nur in der klassischen, öffentlichen oder privaten Unternehmung werden Produktionsfaktoren im Interesse der Leistungserstellung zusammengeführt. Wirtschaftlich werthafte Leistungen, also ökonomische Güter, erstellen auch Schulen, das Militär, das Sozialversicherungssystem, oder das Bauplanungsamt, ohne daß eine Betriebswirtschaftslehre dieser von der klassischen Unternehmung strukturell verschiedenen Organisationen bereits ausgeformt vorläge.

Dem gegenüber, und durchaus im Hinblick auf die Analyse östlicher Wirtschaften im Umbruch, will Richard Portes, da es keine allgemeine Theorie der Transformation gäbe, sich vor allem auf die "tools of supply and demand in a general equilibrium context" verlassen, obwohl doch diese Wirtschaften im Umbruch keineswegs als gleichgewichtig oder an Gleichgewichten orientiert beschrieben werden können. Vgl. Richard Portes, "Integrating the East: Reciprocal Lessons from German and Central European Experience". Jahrestagung 1994 der Gesellschaft für Wirtschaftsund Sozialwissenschaften - Verein für Socialpolitik, Jena 28. bis 30. September 1994 - Die Wettbewerbsfähigkeit der ostdeutschen Wirtschaft: Ausgangslage, Handlungserfordernisse, Perspektiven. 
verbandlichen, auf Protektion gerichteten Lobbyismus in Beziehung bringt - der bekanntlich zu einer Benachteiligung der Konsumenten führt und bei Akkumulation zu einem gesellschaftlichen Suboptimum - so drängt sich doch die Frage auf, warum nicht durch politischen Entscheid eine Umkehrung des Prozesses zustandekommt, da doch das Mehrheitswahlrecht den Konsumenten die entscheidenden Karte in die Hand gibt und sich eine Wahlplattform unschwer vorstellen läßt, die bei Verfassungsänderung das Freerider-Problem neutralisiert. Auffällig ist aber, daß trotz gelegentlicher Unmutsäußerungen gegen einzelne Erscheinungsweisen des verwaltenden Staates mit weitreichenden Reprivatisierungsforderungen nur in Ausnahmefällen politischer Erfolg zu erzielen ist, wobei das Kalifornische Steuerreferendum Proposition 13 als Ausnahme gelten mag, die vor mehr als einem Jahrzehnt die Regel bestätigt hat ${ }^{8}$.

Die Folge dieser Erwägung ist, daß wir, ehe nicht die Bestimmungsgründe des Strukturwandels bekannt sind, diesen mit Mitteln der ökonomischen Theorie auch nicht beurteilen können. Ehe wir nicht über eine Analyse seiner Dynamik verfügen, muß jede Kritik des Strukturwandels sich vorhalten lassen, daß die Unmöglichkeit der Entfaltung gegenläufiger Kräfte nicht überzeugend dargelegt ist. ${ }^{9}$ Solange aber das Verfahren offen ist, Aktion und Reaktion gleiche Chancen haben, ist es nicht offensichtlich, warum nach Ablauf des Prozesses ein sich einstellendes Gleichgewicht nicht auch ein Optimum darstellen kann. Gemeint ist ein Optimum im Pareto-Sinne derart, daß eine Besserstellung einer Partei nur auf Kosten einer Schlechterstellung mindestens einer anderen Partei möglich ist. Nur eine Analyse der Bestimmungsgründe des gesellschaftlichen Wandels kann uns auch in die Lage versetzen zu beurteilen, ob ein bestimmter Entwicklungsprozeß noch im Gange ist und in sich die Chance seiner eigenen Umkehrung enthält, oder ob individuelle, auf Besserstellung gerichtete Einzelentscheidungen die Richtung eines gesellschaftlichen Entwicklungsprozesses bereits eindeutig festlegen.

Da die normative Beurteilung des Strukturwandels, der den Ausgangspunkt unserer Überlegungen bildet, unweigerlich im Spekulativen enden muß, soll es insoweit mit diesen Bemerkungen auch sein Bewenden haben. Der Rest meiner Ausführungen gilt ausschließlich der Möglichkeit einer ökonomischen Analyse im Rahmen der positiven Theorie. Die Frage lautet daher: Wie wird im wirtschaftlichen Bereich und wie wird im politischen Bereich Bewegung erzeugt? Insbesondere: wo liegt das Bewegungselement im politischen Sektor, das diesem zu so unerwartet starker Blüte verhilft und einen Transformationsprozeß ermöglichen kann? Die Frage setzt zunächst voraus, daß der Referenzzustand zur Bewegung, die Ruhe, definiert wird. In der Ökonomie haben wir es daher mit dem Begriff des

Gleichgewichts $\mathrm{zu}$ tun als einem Begriff, der der Klärung bedarf, weil er in der Volkswirtschaftslehre sehr unterschiedlich verwendet wird.

$8 \quad \mathrm{Zu}$ den üblichen Verfahren, die Bereitstellung öffentlicher Güter über den politischen Prozeß zu organisieren, gehören unter anderem Referenden, Volksbegehren und dergleichen. Vgl. die Beiträge in der Sonderausgabe von Kyklos. 47.3, 1974: Special issue: Democratic and Federal Rules for Future Europe.

$9 \quad$ Das Problem wird angesichts der nach wie vor offenen Frage nach den Bestimmungsgründen des Wachtums der öffentlichen Haushalte und Ausdehnung der Funktionen öffentlicher Körperschaften (Wagner's Gesetz) besonders deutlich. Für einen Überblick vgl. Borcherding (1977)). 
Der Gleichgewichtsbegriff gehört als zentrale Kategorie der Nationalökonomie zu jenen Konzepten, die sich als Folge einer intensivierten theoretischen Bemühung insoweit verselbständigt haben, als sie dem Außenstehenden nicht mehr verständlich sind. Zum Beispiel arbeitet die allgemeine Gleichgewichtstheorie mit stark formalisierten Konzepten und gibt Gleichgewichtsbedingungen an, die sich nicht mehr ohne weiteres umgangssprachlich übersetzen lassen ${ }^{10}$. Wenn im folgenden von "Gleichgewicht" die Rede ist, so wird damit nicht auf die technischen Gleichgewichtsbedingungen, etwa im Sinne des Arrow-Debreu-Modells abgestellt, noch auf spieltheoretische Formulierungen, sondern auf deren gemeinsamen politischökonomischen Hintergrund, so wie er weniger auf Walras als auf Pareto zurückgeht. Ich möchte dies anhand von drei Zitaten verdeutlichen. "Der Gleichgewichtszustand eines Systems ist dann gegeben, wenn sich das System in einem Zustand befindet, in dem die Regeln, die die Wirkungsweise des Systems und damit die Tranformation von Inputs und Outputs bestimmen, dazu führen, daß der Zustand erhalten bleibt." Weintraub 1974, 11.

Insofern bezieht sich Weintraub auch auf nicht marktliche Systeme.

Oder Weintraub in Anlehnung an Hicks "Wenn ein Gleichgewicht 'stabil' sein soll, dann muß sich das zeitweilige Gleichgewicht einer Periode an jenes der nächsten bruchlos anschließen, so daß alle Märkte die Entscheidungen der verschiedenen wirtschaftlichen Entscheidungsträger aufeinander abstimmen können. Da es keine perfekten Zukunftsmärkte geben kann, gibt es keine Lösung, die ein für allemal gültig ist. Statt dessen bilden das Geld, die Kapitalgüter und die Finanzaktiva die einzigen Bindeglieder über den Zeitablauf hinweg, zum Beispiel, wenn die Entscheidung in der ersten Woche Geld zu erhalten das Einkommen sicherstellt, das in der zweiten Woche ausgegeben werden kann. Die Mechanismen, die die intertemporalen Strukturen der Entscheidungen bestimmen, beruhen durch und durch auf Erwartungen. Preiserwartungen hängen aber von historischen und zeitgenössischen Preisen ab und aus diesem Grunde bewirkt jede Preisänderung eine Änderung in den Preiserwartungen und auf diese Weise auch eine Veränderung des temporären Gleichgewichts. Mehrere aufeinanderfolgende Änderungen führen mit der Zeit zu einer Beruhigung, oder sie tun dies nicht, je nach den Eigenschaften "des Geldes und der Wertpapiere, jener sonderbaren Dinge, die man nicht um ihrer selbst willen nachfragt, sondern nur deshalb, um in der Zukunft Güter dafür zu erwerben."' (Weintraub 1979, 57 mit Bezug auf Hicks 1939, 259). Diese Definition gilt für Wirtschaften im Umbruch nur bedingt, da sie nur eingeschränkt mit Geldwährung arbeiten. Öffentliche Haushalten mit weichen Rahmenbedingungen, fallen außerhalb diese Bestimmung des Gleichgewichtes.

Als drittes Beispiel mit noch begrenzterer Anwendungsfähigkeit kann uns Krelles Definition der statischen Duopol-Lösung gelten: "Die Paretomenge ist die Menge derjenigen Auszahlungen, bei deren Realisierung es nicht nötig ist, durch irgendeine Koordination Strategien für irgendeine Firma eine höhere Auszahlung zu erreichen, ohne die Auszahlung für zumindest eine Firma zu verringern". (Krelle 1976, 390)

Für unsere Fragestellungen kommt es nun darauf an, herauszufinden, wie es kommt, daß wirtschaftliche und politische Systeme nicht $r$ e g e $1 \mathrm{~m}$ ä $\beta$ i g vorhersehbar funktionieren, warum die auf Ände r u n g e n reagierende Erwartungsbildung so wesentlich ist bzw. wie der Impuls 
in der Erklärung zu fassen ist, der die Auszahlungen verändert und Firmen vom vorherigen Marktgleichgewicht sich entfernen läßt.

Dieser Motor des Wandels, der in einer am Gleichgewicht orientierten Analyse denkbarerweise nicht vorkommen kann, dieses Bewegungselement wird in der ökonomischen Theorie U n t e r $\mathrm{n}$ e h m e r genannt. Entsprechend soll das Bewegungselement des politischen Prozesses mit dem Begriff politischer Unternehmer bezeichnet werden. Der Prozeß findet notwendigerweise in einer Ordnung statt.

Der erste Abschnitt der nachfolgenden Ausführungen soll einen Überblick über den Begriff der Ordnung geben, der zweite ist dem Unternehmer in der ökonomischen Theorie gewidmet. Der dritte gilt dem Versuch einer verfahrenstheoretischen Interpretation der Funktion des Unternehmers in Prozessen der Allokation und Verteilung. Das sind wirtschaftliche Verfahren. Der vierte Abschnitt betrifft den Zusammenhang zwischen der Unternehmerfunktion und der Möglichkeit, daß wirtschaftliche Verfahren zu Gleichgewichtszuständen führen, die wohlfahrtstheoretisch als optimal bezeichnet werden können. Mit diesen Ausführungen wird also der Versuch gemacht, sich den normativen Problemen, die wirtschaftlicher Wandel unweigerlich mit sich bringt, wenigstens insofern zu stellen, als dies die volkswirtschaftliche Theorie erlaubt. Wie erwähnt, muß eine Gesamtbeurteilung des Prozesses gesellschaftlichen Wandels durch den Theoretiker abgelehnt werden, was aber nicht ausschließt, daß notwendige Bedingungen für ein Wohlfahrtsoptimum genannt werden können. Aufgrund dieser Ausführungen versuche ich im fünften Abschnitt, skizzenhaft Elemente einer Theorie des politischen Unternehmers zusammenzutragen. Teil sechs ist dem Wirtschaftsstil als analytischer Kategorie gewidmet. Der siebte Teil enthält die Anwendungen auf Probleme der "Transformationsökonomien", also jener östlichen Wirtschaften, die sich seit der "Wende" von 1989 im Umbruch befinden, ohne daß der Endzustand auf den hin sie sich entwicklen, nun sich schon deutlich abzeichnete. Eine Fülle von der Wirtschaftspresse entnommenen Einzelskizzen wird in das zuvor aus den Kategorien Unternehmer und Stil entworfene Raster projiziert. Die wirtschaftlichen Anwendungen auf Innovation und Kapitalbildung stehen bei dieser Projektion im Vordergrund. Dieser Versuch wird im achten Abschnitt noch einmal kritisch hinterfragt.

\section{Die Ordnung in der politisch-ökonomischen Theorie}

Der wirtschaftliche Wandel in den östlichen Transformationsländern ist augenblicklich deshalb so schwer zu beurteilen, weil es keinen Ordnungsrahmen gibt, in den wir ihn stellen können. Es ist ja wie gesagt nicht zu erwarten, daß sich diese Wirtschaften in Marktwirtschaften verwandeln so, wie wir sie etwa in Nord-Amerika, Groß-Brittanien oder Frankreich kennen. Dies ist schon deshalb nicht möglich, weil diese drei genannten Länder unterschiedliche Wirtschaftsstile entwickelt haben, und die Wirtschaftspolitiker auch von unterschiedlichen Ordnungsvorstellungen geleitet sind. Um den Begriff der Ordnung so, wie er der Wirtschaftspolitik unterliegt deutlich zu machen, greife ich auf eine Episode aus der deutschen Wirtschaftspolitik nach dem Kriege zurück, in der der Begriff der Wirtschaftsordnung eine wesentliche Rolle gespielt hat. Ich beziehe mich auf die Mitbestimmung, und insbesondere auf die endgültige Festschreibung der Mitbestimmung durch das Gesetz von 1976, das auf breiter politischer Grundlage ruhend doch von vielen Theoretikern der Wirtschaftspolitik unter dem Aspekt der Marktkonformität mit Zurückhaltung betrachtet 
wurde.

Viele Kritiker der Mitbestimmung sahen einen Konflikt zwischen der Wirtschaftsordnung und den Mitbestimmungsinstitutionen. Dieses Argument hat in seinem rechtlichen Gewand eine erhebliche Rolle vor dem Bundesverfassungsgericht gespielt. Unter Rückgriff auf die Erörterungen oben wird in diesem Abschnitt geklärt, in welcher Hinsicht das volkswirtschaftliche Konzept der Wirtschaftsordnung in einem Falle wie der Mitbestimmung staatsrechtliche und damit wirtschaftspolitische Bedeutung gewinnen kann.

In ihrer Verfassungsbeschwerde gegen das Mitbestimmungsgesetz vom 4. Mai 1976 führten die Beschwerdeführer unter Rückgriff auf das Kölner Gutachten ${ }^{11}$ aus, die erweiterte Mitbestimmung sei an den normativen Garantien des institutionellen Zusammenhangs der Wirtschaftsverfassung zu messen. Sie trete in einen Widerspruch zu verfassungsrechtlichen Gewährleistungen und zu dem Ordnungs- und Schutzzusammenhang, der aus den Grundrechten für die Wirtschafts- und Arbeitsverfassung des Grundgesetzes entnommen werden könne. ${ }^{12}$

Dagegen führten diejenigen Stellungnahmen, insbesondere das Frankfurter Gutachten ${ }^{13}$ die das Mitbestimmungsgesetz mit dem Grundgesetz für vereinbar hielten, aus, die verfassungsrechtliche Würdigung seiner Auswirkungen könne nicht von einer Wirtschaftsverfassung ausgehen. Eine solche habe das Grundgesetz nicht geschaffen, sondern es sei insoweit bewußt offengehalten worden, und gerade auf dem Gebiet der Wirtschaftsordnung erfreue sich der Gesetzgeber eines weiten Gestaltungsspielraums. Diese Gestaltungsfreiheit umfasse die Prärogative des Parlaments bei der Prognose der Auswirkungen eines wirtschafts- und sozialpolitischen Gesetzes. Sie könne nicht mit Hilfe einer Argumentation aus dem Ordnungs- und Schutzzusammenhang der Grundrechte eingeschränkt werden. ${ }^{14}$

Das Verfassungsgericht selbst äußerte sich über den Problemkomplex dahingehend, das Mitbestimmungsgesetz regele einen Ausschnitt komplexer, schwer übersehbarer Zusammenhänge und bewirke wesentliche Veränderungen der Wirtschaftsordnung. ${ }^{15}$ Die Prüfungsmaßstäbe eines "institutionellen Zusammenhanges der Wirtschaftsverfassung" und eines "Schutz- und Ordnungszusammenhanges der Grundrechte" aber fänden im Grundgesetz keine Stütze, ${ }^{16}$ sodaß

Vgl. Peter Badura, Fritz Rittner, Bernd Rüthers, Mitbestimmungsgesetz 1976 und Grundgesetz: Gemeinschaftsgutachten ("Kölner Gutachten"). München: Beck 1977

13 Friedrich Kübler, Walter Schmidt, Spiros Simitis, Mitbestimmung als gesetzgebungspolitische Aufgabe: Zur Verfassungsmäßigkeit des Mitbestimmungsgesetzes 1976. Baden Baden: Nomos 1978 ("Frankfurter Gutachten"). Das Gutachten war von der Bundesregierung, vertreten durch den Bundesminister für Arbeit und Sozialordnung, in Auftrag gegeben und dem Bundesverfassungsgericht vorgelegt worden. Das Frankfurter Gutachten geht auf das Kölner Gutachten bereits ausführlich ein. 
diese auch nicht als verfassungsrechtliche Argumente gegen das Mitbestimmungsgesetz eingewandt werden könnten.

Diese Stellungnahme der Verfassungsrichter ist an und für sich nicht besonders überraschend; denn sie steht im Einklang mit der ständigen Rechtsprechung. ${ }^{17}$

Überraschend ist vielmehr, daß die Beschwerdeführer in ihrer verfassungsrechtlichen Argumentation auf das Konzept der Wirtschaftsordnung überhaupt zurückgegriffen haben. Man könnte diese Frage für wenig zweckmäßig oder von allenfalls historischem, prozeßstrategischem Interesse halten, wenn es sich bei der juristischen Doktrin von der Wirtschaftsverfassung lediglich um ein von der Rechtslehre entwickeltes staatsrechtliches Konstrukt handelte, das vor dem Verfassungsgericht keinen Bestand hatte und infolgedessen auch seine faktische Bedeutung einbüßte. Insofern steht ganz außer Frage, daß die Doktrin von der Wirtschaftsverfassung nur noch staatsrechtshistorisches Interesse beanspruchen kann. Die juristische Doktrin von der Wirtschaftsverfassung aber ist ihrerseits ein etwas eigenwilliger, von Ernst Rudolf Huber ins Rechtspolitische gewendeter Ableger einer staatsphilosophischen Lehre, die als Handlungsethik auf theoretisch ökonomischen Fundamenten ruht. Sie ist sozusagen ein Ableger der Freiburger Schule der Nationalökonomie, die ja traditionell ethische und volkswirtschaftliche Belange miteinander verknüpft hat. Sie ist eine abstrakte Theorie sozialer Ordnungen, nicht eine staatsrechtliche, auf eine bestimmte Verfassung bezogene. Auch gibt es keinen Hinweis im Grundgesetz, daß die Väter dieser provisorischen Verfassung sich hätten die staatsrechtlichen Auffassungen der Freiburger Schule zu eigen machen wollen.

Dieser juristische Ableger einer volkswirtschaftlichen Lehre hat allerdings niemals Gelegenheit gehabt, sich zu vollem Wuchs zu entfalten und Blüten zu treiben, da er immer wieder vom Verfassungsgericht zurückgeschnitten wurde, gleichwohl ein üppiges Blattwerk unermüdlich ausbreitet. Dies hat seinen guten Grund. Der Staatsrechtslehre fehlt bislang eine Theorie, die wirtschaftliche lnterdependenzeffekte in den Blick rücken könnte. Die Lehre von der Wirtschaftsverfassung vermag dies, ist aber aus normativen Gründen nur mit Einschränkungen akzeptabel.

Die Diskussionslage ist theoretisch besonders pikant, weil eine, wie wir oben sahen, in sich schlüssig ausformulierte Rechtstheorie, die auf methodisch volkswirtschaftlicher Grundlage beruht, nun staatsrechtspraktisch auf verfassungsrechtliche Probleme angewandt werden soll, insoweit aber von der Verfassungsrechtsprechung nicht honoriert wird. Da es sich bei dieser Lehre aber von vornherein nicht um eine bestimmte Verfassung interpretierende staatsrechtliche Doktrin, sondern um eine philosophische (genauer ethische) Gesellschaftstheorie auf ökonomischer Grundlage handelt, geht die Kompetenz eines Verfassungsgerichtes freilich auch nur soweit, die Anwendung der Lehre auf eine bestimmte Verfassung und ihre Umarbeitung in eine staatsrechtliche Doktrin zu verwerfen.

Damit ist aber über die Gültigkeit der Gesellschaftstheorie, aus der - wie wir jetzt wissen,

17 Vgl. bereits BVerfGE 4, 7 (17ff.) ("Investitionshilfe") Eine ausführliche Erörterung des Zusammenhanges findet sich z.B. bei Jürgen Backhaus, Öffentliche Unternehmen: Zum Wirtschaftsrecht, den Funktionen und Rechtsformen öffentlicher Unternehmen. Frankfurt: Haag und Herchen 1980 (2), S. 128 ff. m.w.Nachw. 
unwirksam - eine staatsrechtliche, auf das Grundgesetz bezogene, Doktrin entwickelt worden ist, überhaupt nichts gesagt. Im Gegenteil müssen wir, da diese philosophische Gesellschaftstheorie auf erfahrungswissenschaftlicher, nämlich volkswirtschaftlicher Grundlage beruht, mit einem Spannungsverhältnis zwischen verfassungsgerichtlichen Verdikt und (im Prinzip) empirisch testbaren Aussagen rechnen, die Falsifikationsversuchen standhalten. Um diesen gordischen Knoten aus politisch-ökonomischen und staatsrechtlichen Argumentations- und Theoriesträngen nicht auf Alexandrische $\mathrm{Art}^{18} \mathrm{zu}$ zertrennen, sei im folgenden zunächst einer einfacheren und sehr viel konkreteren Variante derselben staatsphilosophischen Richtung nachgegangen; nach Diskussion der Argumentation von Nozick, ${ }^{19}$ die, weil weniger komplex für unsere Zwecke beinahe klarer ist, wird unter Hinweis auf die Anwendung von Lachmann, erörtert, wie die Konstruktion von Hayek im einzelnen auf das Problem der Wirtschaftsordnung angewandt werden kann.

\section{Nozick}

Nozick setzt sich im achten Kapitel (d.h. im zweiten, den Minimalstaat begründenden Teil) seines Werkes "Anarchie, Staat und Utopie" unter anderem mit Mitbestimmungsfragen auseinander. Dies ist für einen amerikanischen, an der Harvard University lehrenden praktischen Philosophen durchaus überraschend. Gleichwohl hat Nozick durchaus prägnant die wesentlichen Einwände zusammengefaßt, die in der Diskussion zur Wirtschaftsordnung im Mitbestimmungskontext vorgetragen werden. Die Auseinandersetzung kann ich hier auf drei Probleme konzentrieren, die in gebotener Kürze wörtlich wiedergegeben werden können.

\section{(1.) Suboptimales Investitionsvolumen ${ }^{20}$}

Wenn Entscheidungen von den Arbeitern einer Fabrik getroffen werden, dann führt das dazu, daß in eine bestimmte Art von Projekten zu wenig investiert wird. Es handelt sich um diejenigen Investitionsvorhaben, deren Erträge später anfallen, sodaß die Arbeiter, die heute darüber entscheiden, davon einen zu geringen Nutzen haben als daß sie nicht das Geld lieber heute verteilten; das kann daran liegen, daß sie später nicht mehr in dieser Fabrik arbeiten werden, oder auch daran, daß sie nur noch wenige Jahre vom Ruhestand trennen.

\section{(2.) Suboptimales Beschäftigungsniveau ${ }^{21}$}

Die Arbeiter, und damit der gesamte Betrieb, haben einen starken Anreiz, die Durchschnittsgewinne (Gewinne pro Arbeiter) statt der Gesamtgewinne zu maximieren. Dann

$18 \quad$ z.B. durch bloße Äußerung eines Ideologieverdachtes

19 Robert Nozick, Anarchy, State, and Utopia. New York: Basic Books 1974

20 Nozick (1974) S. 251 (meine Übersetzung - J.B.)

$21 \quad$ Nozick (1974) S. 251 (meine Übersetzung - J.B.) 
beschäftigen sie aber weniger Personen als ein Betrieb, der alle jene anstellt, deren Arbeit überhaupt noch einen Gewinn abwirft.

\section{(3.) Legitimationsdefizit ${ }^{22}$}

Am wichtigsten ist festzustellen, daß es stets möglich ist, Arbeiterselbstverwaltung auf freiwilliger Basis einzuführen, als freiwillige Handlung von Bürgern in einer freien Gesellschaft.

Damit sind die wesentlichen Probleme angesprochen: Investitions- und Wachstumsverfall, Unterbeschäftigung, Mitbestimmungsoktroi. Der letzte, von Nozick hervorgehobene Punkt, entzieht der Legitimation einer legislativen Reform des Unternehmensrechts im Interesse der Partizipation der Arbeitnehmer jede Basis; also auch insbesondere die Legitimationsbasis für die Einführung der Mitbestimmung durch den Gesetzgeber.

Die beiden erstgenannten Argumente sind aus der theoretischen volkswirtschaftlichen Literatur wohl bekannt. Immer dann, wenn Eigentumsrechte so spezifiziert sind, daß die Verfügungsberechtigten nicht das Eigentum, sondern nur den Nießbrauch haben, ist der Investitionshorizont künstlich beschnitten. Statt über den Gegenwartswert der Sache selbst, etwa hier des Betriebes, können die Verfügungsberechtigten nur über zeitlich bedingte Nutzenströme aus dieser Sache verfügen. Daraus folgt zweierlei. Zum einen ist der zeitlich beschränkte Nießbrauch in der Regel weit weniger wert als die Sache selbst; diese - individuell korrekte niedrigere Wertschätzung liegt dann auch den Handlungen mit der Sache zugrunde. Zweitens wird aber derjenige, der den Nießbrauch statt das Eigentum hat, auch die Ertragsströme so zu manipulieren suchen, daß sie in die Zeit seines Nießbrauchs fallen, nicht aber in einen anderen Zeitabschnitt, insbesondere danach. ${ }^{23}$ Deshalb gewinnt dieses Argument besondere Bedeutung im Zusammenhang mit dem dritten; denn - so wird oft argumentiert - der Gesetzgeber ist versucht, solche Gesetzgebungsvorhaben zu entwickeln und in die Tat umzusetzen, deren Nutzen in der Gegenwart oder unmittelbaren Zukunft, deren Kosten aber in der ferneren Zukunft liegen, wobei er die Höhe dieser Kosten tendenziell vernachlässigen kann. Ich verweise aber hier auf meine modellhaften Überlegungen, die diese pauschalen Ansichten doch erheblich relativieren. ${ }^{24}$

In der arbeiterkontrollierten Unternehmung wird manches Investitionsvorhaben unterbleiben, weil die Ertragsstruktur nicht gegenwartsnah genug ist. Desinvestition ist ebenfalls nicht ausgeschlossen. Auch das Problem des Einsatzes des Faktors Arbeit ist aus der Theorie der Genossenschaften wie aus der jener nachgebildeten Theorie der sozialistischen (illyrischen)

Nozick (1974) S. 252 (meine Übersetzung - J.B.)

23 Die Konsequenzen dieses Grundsatzes lassen sich besonders augenfällig für den politischen Sektor dokumentieren. Vgl. z.B. Richard E. Wagner, "Economic Manipulation for Political Profit." Kyklos 30, 1977, pp. 395-410

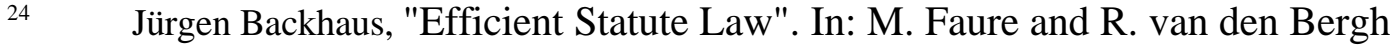
(eds.), Essays in Law and Economics: Corporations, Accident Prevention and Compensation for Losses, Antwerpen, Apeldoorn: Maklu, 1989 (S. 23-32). 
Unternehmung geläufig. ${ }^{25}$ Das Ergebnis beruht aber auf der von Nozick nicht mitgeteilten, für das Ergebnis aber wesentlichen Annahme der gleichmäßigen Entlohnung aller Arbeiter; hier sind andere Strukturen denkbar und auch vorgeschlagen worden. ${ }^{26}$

Auch im erstgenannten Fall ist es möglich, die durch das Auseinanderfallen von Eigentum und Verfügungsmacht (Verkürzung des Eigentums auf den Nießbrauch) hervorgerufene Gefährdung der volkswirtschaftlichen Effizienz zu beseitigen. Verlangt ist aber nur das Zusammenfallen von Eigentum und Verfügungsmacht; während Anforderungen an die Identität des Eigentümers nicht gestellt werden. Daraus folgt für Nozick die Ausstattung des Partizipationsrechts mit der Übertragbarkeit und die Notwendigkeit, eine Austauschinstitution (Markt oder Börse) für diese übertragbaren Partizipationsrechte herzustellen. Diese Korrekturvorschläge freilich weichen in charakteristischer Weise von den in der Literatur im Vordergrund stehenden, nach dem Vorbild demokratischer Abstimmungen ausgestalteten, partizipativen Institutionen (im Vorschlag, in der Gesetzgebung, oder auch in der Praxis erprobt) ab. Deshalb stellt sich für Nozick die Frage nach der Legitimität gesetzgeberischer Wirtschaftsreformmaßnahmen, die Teile der Wirtschaftsverfassung ändern, grundsätzlich nicht nur politisch, sondern auch aus volkswirtschaftlicher Sicht. Dies ist aber überraschend; die Volkswirtschaftslehre wird von der nichtakademischen Öffentlichkeit ebenso wie von Vertretern anderer Disziplinen typischerweise nicht als eine Wissenschaft angesehen, die politische Entscheidungsträger begründet mit normativen Sätzen konfrontiert. Aussagen zur Legitimität wirtschaftspolitischer Maßnahmen aber haben jedenfalls den Anschein des Normativen und fordern dazu heraus, denjenigen, die solche Aussagen vortragen, nun ihrerseits die Frage nach der politischen oder gesellschaftlichen Legitimation zu stellen. Tatsächlich ist aber bei genauerem Hinsehen diese Frage ebenso wie der Anschein, der sie herausforderte, unbegründet. Es handelt sich nämlich bei den in Frage stehenden wirtschaftstheoretischen Aussagen, jedenfalls so weit wie die Begründungsbasis trägt, nicht um normative, sondern um positive Aussagen, die freilich auch einen etwas anderen Inhalt als den bei Nozick dargestellten haben.

\section{Lachmann}

Da in diesem Schrifttum, auf das ich mich hier beziehe, wegen der Nähe der Thematik zu verfassungspolitischen Auseinandersetzungen der Grat zwischen normativen Erörterungen und positiver Analyse schmal ist, lohnt sich eine präzise Rekonstruktion der Argumentation umso mehr, als habhafte Früchte einer volkswirtschaftlichen Analyse, die erfahrungswissenschaftlichen Kriterien standhalten, rar und deshalb begehrt sind. Die von Noziek verkürzt vorgetragene und zur politisch philosophischen Argumentation gewirkte gedankliche Kette findet sich bei Lachmann in Anwendung auf die Fortentwicklung der Institution der Mitbestimmung. ${ }^{27}$

25 Vgl. einen Überblick bei Jürgen Backhaus, Ökonomik der partizipativen Unternehmung I. Tübingen: Mohr (Siebeck) 1979, Kap. 7

$26 \quad$ Vgl. James Edward Meade, "The Theory of Labour Managed Firms and of Profit Sharing.” Economic Journal 82, 1972, S. 402-428

$27 \quad$ Vgl. Ludwig M. Lachmann, "The Flow of Legislation and the Permanence of the Legal Order." Zur Verfassung der Freiheit. Festgabe für Friedrich August von Hayek zur 
Diese Gesetzgebung, und er bezieht sich insbesondere auf das Gesetz von 1976, sei deshalb zu kritisieren, weil sie nicht den Prinzipien des Unternehmensrechts folge, die sich ihrerseits aus einer Analyse der marktlichen Ordnung als einer natürlichen Ordnung, d.h. in diesem Kontext einer Katallaxie folgern lassen. Zwar sei das Unternehmensrecht selbst nicht eine natürlich gewachsene Ordnung, da es seinerseits Produkt gesetzgeberischer Akte und insofern nicht spontan entstanden sei. Aber $^{28}$ das Gesellschaftsrecht ist, kurz gesagt, die gemeinsame Schöpfung sowohl der Marktkräfte als auch legislativer Handlungen, die ihrerseits Ideen verwirklichen, die zur Marktordnung zählen; das ist so das Endprodukt eines langen Interaktionsprozesses zwischen den Geschäftsleuten und den Rechtsgelehrten, die ihre Erfahrung, ihren Geist, und ihre Geschicklichkeit in seine Entwicklung investiert haben (...) Wie oft in der Geschichte haben wir es hier mit einer Institution zu tun, die deutliches Zeugnis vom Geist ihrer Schöpfer gibt; auch wenn diese längst das Feld geräumt haben.

Eine derart blumige Sprache verleitet dazu, dahinter lediglich in romantischer Tradition Mystifizierung des Überkommenen in vehementer Opposition zu gesellschaftlichem Wandel zu vermuten. Tatsächlich hat aber der Status Quo, abgesehen von der pragmatischen Erwägung, daß er notwendiger Ausgangspunkt sowohl jedweden gesellschaftlichen Wandels, Fortschritts und Rückschritts, als auch der einzige Punkt möglichen Beharrens ist, darüberhinaus für sich, jedenfalls dann ein relatives Optimum darzustellen, wenn er Ergebnis einer langen Entwicklungsgeschichte einzelner Schritte ist; die Chance, daß Gelegenheiten zu Paretianischen Verbesserungen, die mindestens einen besser stellen ohne andere zu beeinträchtigen, ausgelassen wurden, ist umso geringer, je länger die Entwicklungsgeschichte dauerte, vorausgesetzt, diese Entwicklungsgeschichte war reich an offenen Situationen, die gesellschaftlichen Wandel schlechterdings erlaubten. Aus dieser Erwägung freilich folgt nicht ein Plädoyer gegen Veränderungen, wie es von Anhängern der neu-österreichischen Richtung wohl manchmal vorschnell vorgetragen wird, sondern - was auch Hayek ausdrücklich betont - die Forschungsstrategie einer auf theoretisch wirtschaftswissenschaftlicher Grundlage vorzunehmenden Rechtsanalyse der (gewachsenen oder als Ergebnis eines interaktiven Prozesses zwischen Gesetzgebung und Rechtsfortbildung) entstandenen Rechtsinstitutionen - gegebenenfalls sogar im Interesse einer Wirtschaftsreform. Die Bedeutung des Konzepts der Wirtschaftsordnung als einer positiven Analyse zugänglichen wirtschaftswissenschaftlichen Kategorie liegt nicht in der Legitimation des Status Quo, auch nicht in der Brücke zwischen Staatsrecht und auf staatsrechtliche Konfliktfragen angewandter Wirtschaftstheorie. Wirtschaftsordnung ist eine Kategorie der ökonomischen Rechtsanalyse und damit Baustein für eine erfahrungswissenschaftliche Theorie der Institutionen, in denen "Wirtschaften" stattfindet. Damit entbehrt die Kategorie normativer Implikationen, insbesonderer solcher, die sich für die Legitimation bestimmter, sei es vorgefundener oder vorgeschlagener, Institutionen in Anspruch nehmen lassen; abgesehen natürlich von jenen Legitimationen, die auf positive Erfahrungswissenschaft Rekurs nehmen.

Auf die Mißverständnisse, die bei der Rezeption ordnungstheoretischer Analysen auftreten können, und denen vielleicht einige Analytiker auch nicht mit der notwendigen Sorgfalt vorbeugen, ist schon frühzeitig von prominenter Seite in eindringlichen Worten hingewiesen worden. Stellvertretend auch für andere Kritiker möchte ich hier Lord Robbins in Anspruch nehmen, der

Vollendung seines 80. Lebensjahres. Ordo 30, 1977, S. 69-78 
1961 in seiner Rezension von Hayeks "Verfassung der Freiheit" ausführte: ${ }^{29}$

Während ich im großen und ganzen der Betonung der Bedeutung des nicht rationalen Elementes in sozialen Gebräuchen und Institutionen nur beipflichten kann, vermag ich gleichwohl eine gewisse Furcht nicht zu verhehlen, daß manche, die weniger differenziert denken, diese Betonung kurzerhand in Hinnahme und Bewunderung ummünzen werden.

Dies freilich hieße, die ordnungstheoretische Analyse ad absurdum führen. Die Idee der spontanen Ordnung, der spontanen Entwicklung von Organisationen, die die Geschichte eines Wettbewerbs relativer Fähigkeiten und technischer Vorteile und insofern ein Verfahren zur Nutzung und Entwicklung des Erbes menschlichen Wissens ist, das in dieser Komplexität dem (gesetzgeberischen) Design nicht zugänglich ist, ${ }^{30}$ ist als Kette unbewußter evolutionärer Experimente $^{31}$ anzusehen. Sozialwissenschaftliche Experimente aber beanspruchen, wie Experimente überhaupt, wissenschaftliches Interesse nur im Zusammenhang mit einer Analyse, die erfahrungswissenschaftliche Sätze ableitet, die sich ihrerseits in weiteren Experimenten zu bewähren haben. Unter unterschiedlichsten Entwicklungsbedingungen entstandene und sich wieder und wieder reproduzierende gleichförmige Strukturen, die ggfs. auch gegen die erklärten Absichten und Handlungen auf sozialen Wandel bedachter Gesetzgeber rekurrent auftreten, lassen bei genügender Häufigkeit und Gleichförmigkeit den Schluß auf ihre Effizienz zu. Damit bezeichnet aber Wirtschaftsordnung nicht spezielle Anforderungen an institutionelle Strukturen, speziell etwa im Sinne einer Entsprechung zwischen Ordnungselementen einer Staatsverfassung mit gesellschaftsrechtlichen Strukturen, sondern es handelt sich um allgemeine Prinzipien, die einer Katallaxie entsprechen. Dem allgemeinen Charakter dieser Strukturen übrigens entspricht auch eine Folgerung hinsichtlich der Regelbarkeit der Strukturen. Da die Komplexität einer realisierten Ordnung typischerweise Kenntnisstand und Informationsverarbeitungskapazität einzelner Handelnder, Wirtschaftspolitiker eingeschlossen, übersteigt, sind diese, wenn sie mit ihren Handlungen reale Erfolge statt zeremonielle oder symbolische Gesten beabsichtigen, im wesentlichen auf ordnungspolitische Maßnahmen verwiesen. ${ }^{32}$

Dieses Regelungsproblem nun stellt den Gesetzgeber vor ein rechtspolitisches Problem: daß nämlich Rechtspolitik objektiven rechtsinstitutionellen Schranken unterworfen ist. Nicht aus normativen, sondern aus rechtspragmatischen Gründen im Interesse des rechtspolitischen Erfolges muß sich der Gesetzgeber Beschränkungen unterwerfen, die sich aus der bereits verwirklichten ob durch Gesetzgebung oder rechtsinstitutionelle Entwicklung bleibt unerheblich - Rechtsordnung ergeben: Es ist der ganze Komplex von Regelungen, die tatsächlich in einer bestimmten

29 Lord Lionel Robbins, "Hayek on Liberty." Economica 28, 1961, S. 66-81 (70) (meine Übersetzung - J.B.)

$30 \quad$ Vgl. Friedrich August von Hayek, "The Use of Knowledge in Society." American Economic Review, 35, 1945, S. 519-530

31 Vgl. Friedrich von Hayek, Law, Legislation, and Liberty: A New Statement of the Liberal Principles of Justice and Political Economy 1, "Rules and Orders". Chicago: The University of Chicago Press 1973, S. 2

32 Vgl. Friedrich von Hayek, Law, Legislation, and Liberty: A New Statement of the Liberal Principles of Justice and Political Economy, 11, "The Mirage of Social Justice". Chicago: The University of Chicago Press 1976 
Gesellschaft beobachtet werden, die ihrerseits festlegen, welche spezielle Regelung aus Gründen der Rationalität durchgesetzt werden kann oder sollte. ${ }^{33}$

"Sollte" hat hier nicht normative, sondern ausschließlich pragmatische Bedeutung und ist am rechtspolitischen Erfolg orientiert. Offensichtlich ist aber dieser rechtspolitische Grundsatz alles andere als spezifisch. Er gibt für verfassungspolitische Auseinandersetzungen über konkrete gesetzgeberische Vorhaben gar nichts her, wenn er mehr sein soll als das Motto einer Rechtsanalyse, die ihrerseits die rechtstatsächlichen Bedingungen herausarbeitet, denen die Rechtspolitik unterliegt. Diese Ausführungen decken sich genau mit der Ansicht des Bundesverfassungsgerichtes, das, aus der Pflicht des Gesetzgebers zur Schaffung funktionsfähiger Ordnungen konkret doch nur Sorgfaltspflichten im Gesetzgebungsverfahren und ein Korrekturgebot für den Fall folgerte, daß sich die gesetzgeberische Prognose über die Gesetzgebungsfolgen nicht bewahrheiten sollte.

Wir haben es hier nicht mit einem prinzipiellen Defizit der Ordnungstheorien zu tun, sondern mit einem Merkmal ihres gegenwärtigen Entwicklungsstandes, das bei untauglichen Versuchen der Theorieanwendung deutlich hervortritt. Die theoretischen Aussagen halten sich derzeit, was angesichts des Umfanges der bis heute vorliegenden Forschung auch nicht verwundern kann, noch im allgemeinen, worauf auch in der englischsprachigen Rezeption hingewiesen wird, ohne daß damit eine Einschränkung der Bedeutung dieser Forschungsrichtung beabsichtigt wäre. ${ }^{34}$

Der ordnungstheoretische Ansatz ist also als Aufforderung zu - letztlich empirisch orientierter ökonomischer Rechtsanalyse aufzufassen, gänzlich untauglich für Legitimationsbemühungen mit Bezug auf bestehende oder vorgeschlagene Rechtsinstitutionen. Wirtschaftsordnung ist insofern eine positive erfahrungswissenschaftliche Kategorie. Anders als im Staatsrecht hat sie in der Volkswirtschaftslehre keine normativen Implikationen.

\section{Nozicks Beispiele}

Wir können dies anhand des von Nozick gewählten Beispiels demonstrieren. Wie erinnerlich verlangt die vertragstheoretische Sicht der Unternehmung, die die Unternehmung als Organisation kennzeichnet, in der mehrere Inputeigentümer zusammenarbeiten, daß eine Partei, die nicht selbst Inputeigentümer zu sein braucht, für alle Inputeigentümer zentraler Vertragspartner sein muß und

$33 \quad$ Vgl. Friedrich August von Hayek (1976), S. 51

34 "Ehe ich diesen Fragen in den nachfolgenden Abschnitten im einzelnen nachgehe, möchte ich doch kurz einen Aspekt der Hayekschen Darstellung gesellschaftlicher Regeln erwähnen, der auch die Grenzen seines Ansatzes illustriert. Hayek sagt, daß die gesamte Ordnung nicht unbedingt daraus entsteht, daß einzelne Individuen Regeln gehorchen. Individuelle Antworten auf besondere Umstände werden nur dann eine Gesamtordnung ergeben, wenn die Individuen solchen Regeln gehorchen, die eine derartige Ordnung konstituieren. Aber wir wissen im voraus nie, welche Regeln eine Ordnung konstituieren werden. Hayek sagt, daß diejenigen Gruppen, die Bestand haben und sich ihrer Umgebung besser anpassen als andere, dies genau deshalb tun, weil sie sich das beste Regelungssystem gegeben haben. Es ist aber offensichtlich, daß wir nur im nachhinein wissen, welche Regeln für das Überleben am besten sind, wenn wir uns nämlich diese Gruppen ansehen." Brian Barry, Hayek's Social and Economic Philosophy. London: Macmillan 1979, S. 82 (meine Übersetzung - J.B.) 
über ein Bündel von Rechten verfügt. Dieses Bündel besteht aus ${ }^{35}$

\section{A. USUS}

1. Kontrolle der Inputs und Outputs

2. Bestimmungsrecht über die Zusammensetzung der Gruppe oder des "Teams" der Produzenten

3. Zusammenfassung der Verträge mit allen Inputfaktoreigentürnern in einer Hand

\section{B. USUS FRUCTUS}

4. Dem Recht auf den Ertrag und

\section{ABUSUS}

5. dem Recht, die Organisation zu verkaufen oder aufzulösen.

Nozick war nun davon ausgegangen, die Arbeiter hätten in der Unternehmung nur das Recht vier, ggfs. auch eines der drei ersten Rechte, auf jeden Fall aber nicht das fünfte Recht, die Unternehmung als ganze zu verkaufen oder aufzulösen. Nehmen wir also in Nozicks Beispiel an, daß der Gesetzgeber eine Unternehmensstruktur vorschlägt, der zufolge die Kapitaleigentümer die Rechte eins bis drei sowie fünf erhalten, die Arbeiter aber das Recht vier. In diesem Fall können wir davon ausgehen, daß in der Unternehmung kein Ertrag mehr anfällt; daß vielmehr die Kapitaleigentümer durch geeignete Re-Kontrahierung mit anderen Inputfaktoreigentümern die Firma so leiten werden, daß ihre Gewinne als Erträge eines der Inputfaktoreigentümers auftauchen, z.B. als Zinsen des Kapitals. Diese Form ist z.B. in Konzernen durchaus gebräuchlich und sie impliziert keine wesentlichen Restriktionen für die effiziente Organisation und Führung der Unternehmung.

Wenn andererseits die Arbeitnehmer keinen Lohn erhalten, sondern ihr Recht auf den Ertrag an die Stelle des Lohnes gesetzt wurde, so können wir davon ausgehen, daß der den Arbeitnehmern zufließende Ertrag grosso modo ihren Grenzwertprodukten entsprechen wird. Das ganze System wäre dann zwar etwas ungewöhnlich, und man würde davon ausgehen müssen, daß die Unternehmung so zu führen wäre, daß ein möglichst konstanter Ertrag erwirtschaftet werden kann. Denn Arbeitnehmer ziehen in der Regel sichere Einkommen unsicheren (und eventuell sogar im Erwartungswert höheren) Einkommen vor. Auch diese Form ist gebräuchlich, z.B. bei großen Publikumsgesellschaften mit einem Mehrheitsaktionär, der, um ungünstige Bewegungen am Aktienmarkt zu vermeiden, eine stetige Dividendenpolitik durchsetzt, unabhängig von den tatsächlichen Erträgen der Unternehmung. Die stetige Dividende wird durch entsprechende Reservenbildung und Inanspruchnahme dieser Reserven ermöglicht. Diese beiden ersten hypothetischen Beispiele gesetzgeberischer Eingriffe erweisen sich deshalb als unschädlich, weil deren negative Konsequenzen von den Unternehmenseigentümern ausgeglichen werden können.

35 Vgl. Armen A. Alchian, Harold Demsetz, "Production, Information Costs, and Economic Organization." American Economic Review 62, 1972, pp. 777-795 
Radikalere Folgen hätte ein Gegenbeispiel, etwa so, daß den Arbeitnehmern die Rechte eins bis drei und fünf übertragen würden, während die Gesellschafter das Recht vier behalten. Dieses Recht alleine ist praktisch wertlos; die Folge einer solchen gesetzgeberischen Maßnahme muß aber nicht sein, daß die Kapitaleigner hinfort in die Unternehmung nicht mehr investieren. Die Kapitaleigner kennen die Unternehmung, ihre Chancen und Schwächen, und in Berechnungen des Nettogegenwartswertes spielt die Größe "Groll" keine Rolle. Investitionen können aber nur erwartet werden, wenn die Arbeitnehmereigentümer entweder haften oder eine (glaubhafte) Ertragsgarantie abgeben oder aber Direktivrechte über Organisation und Produktion abtreten. Alle drei Alternativen bedeuten, daß die vom Gesetzgeber geschaffene Rechtskonstellation keinen Bestand hat. Haftung bedeutet eine Einschränkung von Recht fünf, Ertragsgarantie eine Umformung des Rechtes vier, und die Einräumung unternehmensinterner Kompetenzen eine Veränderung der Rechte eins bis drei.

Wie wichtig das fünfte Recht ist, zeigt sich, wenn eine Konstellation vom Gesetzgeber gewählt wird, die die Rechte eins bis vier den Arbeitnehmern gibt, das fünfte Recht aber ausschließt oder staatlichen Organisationen vorbehält. Die Nichtverfügung über das Recht, die Organisation zu verkaufen oder aufzulösen, führt dazu, daß Haftungsmöglichkeiten stark eingeschränkt werden. Dies bedeutet andererseits, daß es schwer sein wird, Kapital in die Unternehmung einzuwerben, denn das Recht vier auf den Ertrag kann nicht als Sicherung hingegeben werden, da es nicht sehr viel Sicherheit bietet; die Arbeiter können zwar an der Substanz der Unternehmung zehren, behalten über diesen Prozeß jedoch die Kontrolle, sodaß die Investition nicht durch Substanzwerte gesichert werden kann. Die Folge ist entweder, daß der Kapitalgeber neben dem Recht vier noch weitergehende Befugnisse aus den Rechten eins bis drei erhält, oder aber der Staat, wenn er das Recht fünf sich vorbehalten hatte, zum faktischen Eigentümer der Unternehmung wird.

Das deutsche Mitbestimmungssystem teilt das erste Recht, während es die Rechte zwei bis fünf voll bei den Gesellschaftern beläßt. Das heißt, die Überwachung der Inputfaktoren wird verstärkt. Zwar besteht die Gefahr, daß sie gleichzeitig diffus wird, jedenfalls insofern, als die Repräsentanten eines Inputfaktors dessen Überwachung mit übernehmen; insgesamt ist diese Gefahr aber eher gering, da die Kapitaleigentümer, indem sie das fünfte Recht behalten, Gefahren von ihrem Eigentum abwenden können und dadurch, daß sie die Rechte zwei bis drei behalten und hinsichtlich des ersten noch ein Übergewicht wahren, die Organisation der Unternehmung so bewerkstelligt werden kann, daß Kollusion zwischen Überwachenden und Überwachten nicht im Interesse der beiden Parteien ist.

\section{Ein Ergebnis}

Wir können nunmehr als Ergebnis festhalten: Der staatsrechtliche Begriff der Wirtschaftsordnung stimmt mit dem volkswirtschaftlichen nicht überein. Er ist im übrigen als Folge der Rechtsprechung des Verfassungsgerichts für Grundgesetzfragen irrelevant und kann daher auch von den Volkswirten unbeachtet bleiben. Im übrigen ist der Beitrag, den der Volkswirt zu den im Staatsrecht vorrangigen normativen Fragestellungen leisten kann, als relativ geringfügig einzuschätzen.

Dagegen ist der rechtstheoretische Ordnungsbegriff, der oben anhand der einschlägigen Schriften von Hayeks entwickelt wurde, für das Grundgesetz und rechtspolitische Entwicklungen im 
Geltungsbereich seiner Rechtsordnung von Bedeutung. Er ist aber ein sehr abstrakter Begriff. Die konkreten Folgerungen, die wir aus der ihm zugehörigen Rechtstheorie gezogen haben, stehen weder im Gegensatz zur Mitbestimmungsgesetzgebung noch zur Rechtsprechung des Verfassungsgerichtes. Das Mitbestimmungsgesetz ist kein Maßnahmegesetz, vielmehr integraler Teil einer historischen Entwicklung, stellt keinen unausweichlichen Oktroi dar und steht im übrigen als Folge der Rechtsprechung des Gerichtes unter einem empirisch gefaßten Korrekturgebot. Für die neuer Wirtschaftssysteme ergibt sich so ein weiter, aber nicht unbegrenzter legislativer und wirtschaftspolitischer Ermessensspielraum.

Versucht man endlich, Wirtschaftsordnung noch konkreter als empirisch zugängliche Kategorie der Theorie wirtschaftlicher Rechtspolitik zu verwenden, und dem diente der Versuch einer Kombination der Kriterien von Alchian und Demsetz und der Kritik von Nozick, so besteht Mitbestimmung als Institution diesen einigermaßen stringenten Test glänzend. Die konkreten Mitbestimmungsinstitutionen widersprechen den so gefolgerten wirtschafts-ordnungstheoretischen Kriterien durchaus nicht.

Das Konzept der Wirtschaftsordnung kann damit für die Theorie der Wirtschaftspolitik in der Tat fruchtbar gemacht werden.

\section{Der Unternehmer in der ökonomischen Theorie}

Der Ökonom stößt mit dem Versuch, den Unternehmer zum Gegenstand seiner Theorie zu machen, auf eine Schwierigkeit, die mit der Methode der ökonomischen Theoriebildung selbst zusammenhängt. Die ökonomische Theorie arbeitet ja mit Idealtypen (Weber 1904), die nicht einzelnen, bestimmbaren Individuen entsprechen und deren Handlungsweise auch durchaus nicht getreu abbilden sollen. Der Homo oeconomicus ist eine theoretische Konstruktion und Abstraktion, die Gleichförmigkeiten massenhaft auftretender individueller Entscheidungen in einem Modell integriert, von den Besonderheiten der unverwechselbaren Identität einzelner Individuen, ihren Beweggründen und Entscheidungen aber absieht, weil und soweit sie im Gesamtprozeß nicht zum Tragen kommen. Nun ist eine solche Theorie, wie Schumpeter (1912, I) in klassischer Weise dargelegt hat, inhärent statisch. Eine Theorie der wirtschaftlichen Entwicklung aber muß gerade jene Besonderheiten individueller Handlungsweisen einfangen, die vom Durchschnittlichen abweichen u n d wirtschaftlichen Wandel initiieren. Abstrakt gesprochen heißen diejenigen Individuen, die ein solches initiierendes Verhalten zeigen, Unternehmer.

In frühen Darstellungen der volkswirtschaftlichen Theorie wird der Unternehmer noch anders definiert. Hier erscheint er uns, etwa noch bei Pierstorff im achten Band der dritten Auflage des Handwörterbuchs der Staatswissenschaften (Jena: Fischer 1911) als Mitglied

... einer Klasse selbständiger Produzenten (...), die unter Einsetzung eigenen Kapitalvermögens, in der Regel aber auch eigener Tätigkeit, ferner - soweit Bedürfnis und Möglichkeit gegeben sind - unter Heranziehung und Verwertung fremder Produktionsmittel oder Kapitalvermögensteile und fremder Arbeitskräfte die Produktion wirtschaftlicher Güter und Dienstleistungen auf eigene Rechnung und Gefahr betriebsmäßig organisieren und leiten, um in dem Überschuß der in verkehrsmäßiger Verwertung der produzierten Sachgüter und Dienstleistungen erzielten Erlöse 
Einkommen für sich zu erzielen. (S.95)

Pierstorff hält an dieser Definition fest, obgleich er sich bereits auf Arbeiten Schmollers, Portes, Sombarts und Wiedenfelds (sämtliche Nachweise dort) stützt, die freilich im Rahmen der historischen Schule der Nationalökonomie sehr nachdrücklich auf die Besonderheiten der Unternehmerfunktion für die wirtschaftliche Entwicklung hingewiesen hatten (weitere Nachweise dazu bei Pütz $(1935,12))$.

Die Definitionselemente, die Pierstorff aufzählt, sind nämlich sämtlich nicht für die Charakterisierung des Unternehmers und seiner Funktion in der wirtschaftlichen Entwicklung wesentlich. Auf jedes einzelne kann verzichtet werden. Der Unternehmer muß nicht selbständig sein, um Wandel zu erzeugen (Redlich 1964, 103 und passim). Er muß der Organisation, zum Beispiel der Unternehmung, die ihm zur Durchsetzung seiner Vorstellungen dient, nicht einmal juristisch verbunden sein. Er kann zum Beispiel wirtschaftslenkender Beamter sein. Er muß nicht Produzent sein, so daß er im eigentlichen Sinne wirtschaftlich werthafte Güter herstellte. Der Kriegsunternehmer fällt schwerlich in diese Kategorie, ist aber als Motor des wirtschaftlichen Wandels von entscheidender Bedeutung (Redlich 1956; 1964/65, Soltow 1968, 87). Der Unternehmer muß nicht eigenes Kapital einsetzen. Schumpeter ging sogar davon aus, er finanziere sich ausschließlich mit Fremdkapital (1934, erste Auflage 208, vierte Auflage 104; 1928, 485; 1929, 313). Er muß das Unternehmen, durch das der Wandel herbeigeführt wird, nicht selbst ins Werk setzen, sondern (nur) bestimmen und lenken (Redlich 1964, 158 ff., passim). Er muß nicht auf eigene Rechnung und Gefahr produzieren; Pareto etwa geht von der Regel aus, daß der Unternehmer das Risiko seiner Unternehmungen abwälzt (Pareto, 1935, § § 2232, 2316). Die materielle Motivation kann völlig nebensächlich sein (Baumol 1968, 68, passim; Schumpeter 1911, $172 \mathrm{ff})$.

Insbesondere im Hinblick auf die Theorie des Unternehmergewinns ist die Feststellung wesentlich, daß Unternehmer und Kapitalgeber durchaus nicht identisch sein müssen. Sehr präzise liest man das bei Pareto (1935, § 2231, meine Übersetzung):

Einige Autoren haben, und sie bestehen auch heute noch darauf, wenn von "Kapitalisten" die Rede ist, zwei ganz verschiedene Bedeutungen dieses Begriffes fortwährend erwechselt:

1. Eigentümer von Ersparnissen und solche Personen, die von den Zinsen aus ihrem Vermögen leben und

2. diejenigen, die in Unternehmen alles in Bewegung halten:

die Unternehmer. Diese Verwechslung ist nun wirklich ein großes Hindernis für das Verständnis wirtschaftlicher Sachverhalte, und sogar noch ein größeres Hindernis für das Verständnis allgemein gesellschaftlicher Prozesse.

Tatsächlich verfolgen nämlich diese beiden verschiedenen "Kapitalisten" oft diametral entgegengesetzte Interessen.

Der Gegensatz ihrer Interessen kann sogar noch größer sein als der traditionelle Klassengegensatz zwischen "dem Proletariat" und "den Kapitalisten". Vom wirtschaftlichen Standpunkt aus ist es für den Unternehmer nur von Vorteil, wenn die Zinsen für die Ersparnisse und das Kapital, das er sich borgt, so gering wie möglich sind.

Aus der Sicht der Sparer sollten sie so hoch wie möglich sein. Der Unternehmer profitiert davon, 
wenn die Preise seiner Produkte steigen, während Preissteigerungen anderer Produkte ihn oft wenig berühren, weil er sie durch eigene Preissteigerungen auffangen kann. Aber alle diese Preissteigerungen schaden dem Sparer.

Steuern und Abgaben auf die Güter, die der Unternehmer produziert, schaden ihm auch wenig manchmal nutzen sie ihm sogar, weil sie die Konkurrenz abschrecken. Aber sie schaden stets dem Konsumenten, dessen Einkommen aus Kapitalerträgen besteht.

Im allgemeinen kann der Unternehmer die Kostenerhöhungen überwälzen, die drückende Steuern bei ihm verursachen. Derjenige, der nur von Kapitalerträgen lebt, kann dies nicht. Auch sind Lohnsteigerungen für den Unternehmer, der eine Fabrik betreibt, nur für eine bestimmte Übergangszeit unerfreulich, solange er an bestehende Verträge gebunden ist. Schließlich können sie durch spätere Preissteigerungen wieder ausgeglichen werden. In diesen Fällen haben die Unternehmer dieselben Interessen wie ihre Angestellten,

und beide stehen in Konflikt mit den Kapitaleignern. Das gleiche gilt für Unternehmer und Beschäftigte in Sektoren, die sich staatlicher Protektion erfreuen...

Abgesehen von diesen aus heutiger Sicht nur allzu geläufigen Koalitionen, deren Herausarbeitung Paretos ökonomische Gesellschaftstheorie charakterisiert, ist der Unterschied zwischen dem Unternehmer einerseits, dem Manager andererseits wesentlich, den Pareto und Schumpeter etwa zu gleicher Zeit unterstrichen ${ }^{36}$. Der Unterschied besteht darin, daß der Unternehmer als derjenige, der die Statik aufhebt und Änderungen der gegebenen Verhältnisse herbeiführt, sich grundlegend von dem Manager unterscheidet, der im Rahmen der bestehenden Verhältnisse versucht, so effizient wie möglich zu verfahren (Schumpeter 1911, 158 ff.). Technisch gesprochen handelt es sich darum, daß der Unternehmer die Produktionsmöglichkeiten neu gestaltet und bestimmt, während der Manager versucht, an die Grenze der Produktionsmöglichkeiten so nah wie möglich heranzukommen. Der Unternehmer gestaltet durch die "Durchsetzung neuer Kombinationen die vorhandenen wirtschaftlichen Möglichkeiten" (Schumpeter 1911, 158). Die neue Gestaltung der Produktionsmöglichkeitsgrenze erfolgt durch den Unternehmer in dessen Dispositionsfunktion, durch die Tätigkeit des Unternehmers, nämlich, "richtige Dispositionen" zu treffen (Schumpeter 1911, 178), etwa im Rahmen der neuartigen Kombination von Produktionsfaktoren (Schumpeter $1911,175)$.

Die Zitate und Verweise zeigen deutlich, worauf es bei einer Theorie des Unternehmers ankommt. Der Unternehmer ist der Typus eines wirtschaftliche Akteurs, durch den Dynamik erzeugt wird, durch dessen Handlungen sich Rahmenbedingungen verändern, der neue Kombinationen und Strukturen verwirklicht und so die Voraussetzung für Wachstum schafft, sei dies in wirtschaflicher oder politischer Hinsicht.

Diese Definition freilich hat eine Konsequenz, an der viele Wirtschaftstheoretiker vor allem in der Auseinandersetzung mit Schumpeter Anstoß genommen haben. Wenn man das Prinzip jenes Unternehmers, der das Bestehende in Frage stellt und das Neue verwirklicht, das sich schließlich nur durchsetzen kann, wenn es als besser akzeptiert und von den Managern bis ins letzte perfektioniert wird, zu Ende denkt, dann schafft der Unternehmer als Typus die Voraussetzung dafür, daß seine Funktion irgendwann überflüssig werden muß. Dies führte Schumpeter im

36 Der Begriff des "Managers" freilich ist neueren Datums.

Schumpeter unterschied in seiner Definition den Unternehmer als den "Mann der Tat auf wirtschaftlichem Gebiete" und den scheinbaren Leiter einer Unternehmung, den statischen "Wirt" (Schumpeter 1911, 172). 
zwölften Kapitel seines Buches "Capitalism, Socialism and Democracy" zu pessimistischen Einschätzungen der langfristigen Entwicklungsmöglichkeiten kapitalistischer Systeme ${ }^{37}$. Offensichtlich handelt es sich hierbei um eine langfristige Spekulation in Bezug auf die strukturellen Entwicklungschancen eines ganzen Systems, nicht aber um die apokalyptische Charakterisierung einer bestimmten Gruppe wirtschaftlicher Akteure und gar eines einzelnen Berufsstandes ${ }^{38}$. Die Vorstellung, eine Kette wirtschaftlicher oder sozialer Verbesserungen führe eines Tages dazu, daß ein optimum supremum erreicht sei, von dem aus weitere Verbesserungen nicht mehr möglich sind, setzt eine abgeschlossene und von Außeneinflüssen abgeschottete Gesellschaft voraus, die ihre eigene Identität wegen der Kontinuität der in ihr lebenden Individuen bewahrt und auch die Bewertungsmaßstäbe, nach denen ein solches Optimum zu beurteilen wäre, nicht ändert.

Ähnlich argumentierte auch vor zwei Jahrzehnten Galbraith $(1967,88)$, der den Unternehmer als Apis mellifera bezeichnete. Er befruchte, indem er sich selbst vernichte. Dieser rhetorisch zu wertende Hinweis diente Galbraith dazu, auf seine Einschätzung hinzuweisen, derzufolge die ökonomische Funktion des Unternehmers nicht mehr bei einzelnen Persönlichkeiten, sondern im industriellen Zeitalter in der Technostruktur liege. Eine derartige funktionalistische Dichte vertritt auch Albach (1979). Albach versucht mit dieser Konzeption, wirtschaftspolitisch Aufschluß über

Das Kapitel trägt die bezeichnende Überschrift "Die Wände zeigen Risse" (Crumbling Walls).

38 Die Möglichkeit eines solchen Mißverständnisses zeigt sich sehr deutlich bei Pütz 1934. Da entsprechende Vorstellungen immer wieder anklingen, sei hier dem Wortlaut nach zitiert. "Infolge der Konkurrenz hat der Unternehmergewinn diese Tendenz, sich selbst, das heißt seine volkswirtschaftliche Funktion und Bedeutung, zu beseitigen. Wir kommen also zu dem bemerkenswerten Ergebnis: Hohe Unternehmergewinne sind ein Zeichen für volkswirtschaftlich unfruchtbare Gliederung der Produktivkräfte. Da die sogenannte volkswirtschaftliche Funktion des Unternehmers sich in nichts unterscheidet von der Funktion des Gewinns, dürfen wir sinngesetzlich folgern: Der Unternehmer dient der Volkswirtschaft, indem er sich selbst beseitigt und überflüssig macht. In einer höchst produktiv geordneten Volkswirtschaft gibt es keine Unternehmer!, sondern nur Leiter von Betrieben, die sich ökonomisch nicht wesentlich von Arbeitern unterscheiden. Merkwürdig: Das ökonomische Wesen der Unternehmer liegt in der Selbstaufhebung zugunsten höchster volkswirtschaftlicher Produktivität.

Diese sonderbare Folgerung deckt sich sinngemäß mit unserer früheren Feststellung, daß jene Spezies Mensch, die wir im Wirtschaftsleben Unternehmer zu nennen pflegen, "wesenlos" ist, wenn wir sie als ökonomische Funktion zu begreifen suchen.

An dieser Stelle wird wieder einmal deutlich, wie tief die von Ricardo begründete Wirtschaftstheorie und Wirtschaftsanschaung mit der kollektivistisch-sozialistischen Anschaung insbesondere Marxens zusammenhängt. Man denke: Der Unternehmer ist in seinem ökonomischen Wesen "eigentlich" unproduktiv, und in einer richtig gegliederten Volkswirtschaft gibt es für ihn keinen Raum - er wird zum Arbeiter. Nennen wir den Unternehmer "Kapitalist", dann haben wir hier den reinen Marx". (Pütz 1934, 10 f.).

Jedwede ökonomische oder gesellschaftliche Verbesserung (Pareto improvement) bedingt natürlich, daß, wenn sie durchgesetzt ist, die Aufgabe damit beendet ist und es sich darum handelt, an anderer Stelle oder auf dieser Verbesserung aufbauend weiter zu verbessern. Vergleich auch unten III! 
die Analyse (wünschbarer) Unternehmensstrukturen zu gewinnen. Anders Galbraith, dessen Konzept der Technostruktur sich als methodisch problematisch, weil kaum präzise bestimmbar erwies (Gäfgen, 1974). Galbraiths Argumentation beruht auf der Vermengung der beiden Funktionen des Unternehmers einerseits, des Managers andererseits (vergleiche insbesondere Galbraith 1967, 92).

Dieselbe konzeptionelle Mischung der Funktionen beobachten wir bei den Begründern der jüngeren Chicago- oder Property-Rights-Schule der volkswirtschaftlichen Theorie der Unternehmung. Hier ist der Unternehmer zwar noch einerseits durch die in der Firma, die ein Spezialtypus der Unternehmung ist (Backhaus 1979, I) bewirkte Koordinationsleistung der Produktionsfaktoren gekennzeichnet; er gestaltet eine Unternehmung als Organisation, die Kommunikation zwischen Produzierenden und die Koordination der Produktionsfaktoren besser zu leisten in der Lage ist als dezentrale marktliche Interaktion (Coase 1937). Andererseits sieht dieselbe Schule den Unternehmer als das Oberhaupt einer Hierarchie, dessen hierarchische Position ihm erlaubt, Produktionsprozesse effizient zu steuern, da die Chance, sich das Residuum anzueignen, ihn dazu beflügelt, nicht nur Prozesse optimal zu gestalten, sondern auch Untergebene effizient zu kontrollieren so, daß maximale Leistung (durch Kontrolle) sichergestellt wird (Alchian und Demsetz 1972). Beide Ansätze nun sind aber ineinander verzahnte Elemente derselben volkswirtschaftlichen Theorie der Firma, in deren Begründungszusammengang wechselweise teils auf den Unternehmer (schwerpunktmäßig bei Coase), teils auf den Manager (schwerpunktmäßig bei Alchian \& Demsetz) abgehoben wird, ohne daß diese Funktionen stets voneinander unterschieden würden. Die Konsequenz dieser Unterscheidung bestünde darin, daß der AlchianDemsetzschen Variation die allokationstheoretische Begründung für die hierarchische Organisationform entzogen wäre, die alsdann nur noch auf einer Motivationstheorie beruhen könnte, die ökonomisch nicht ausreichend abgesichert und psychologisch energisch bestritten bleibt (vergleiche auch Backhaus 1979, II.4).

Die Grundlage für diese konzeptionelle Vermengung war bereits bei Frank Knight (1921) gelegt. Unsicherheit führe zu einer Spezialisierung ökonomischer Funktionen aufgrund vierer Tendenzen, deren enge Beziehung zueinander "offensichtlich" $(1971,270)$ sei. Diese Tendenzen sind erstens eine Anpassung des Menschen an bestimmte Beschäftigungen aufgrund ihrer speziellen Kenntnisse und ihres Urteilsvermögens; zweitens eine ähnliche Auswahl aufgrund ihrer Fähigkeit, Entwicklungen richtig vorauszusehen, da einige Arten von Tätigkeiten diese Fähigkeiten dringend erforderten, während sie für andere nicht bedeutsam seien; hier ist das oben bereits angesprochene Problem der Erwartungsbildung zentral; drittens eine Spezialisierung innerhalb produktiverer Gruppen, die dazu führe, daß Personen mit überlegenen administrativen Fähigkeiten (managerial ability), konkretisiert als richtige Voraussicht und die Fähigkeit, andere zu kontrollieren, zur Leitung einer Gruppe berufen seien, die dann ihren Anweisungen folge; sowie viertens eine Spezialisierung zur Risikoübernahme aufgrund der Fähigkeit, Vertrauen in das eigene Urteil zu setzen und hinter eigenen Entscheidungen auch so zu stehen, daß sie durchgesetzt werden. Auch auf den folgenden Seiten wird Management und Unternehmentum wechselweise synonym gebraucht (1971, 282 passim). Das "offensichtliche" Zusammenfallen der Charakteristika, die teils typisch für Management, teils typisch für Unternehmertum sind, bleibt unbegründet.

Paretos Konzeption dagegen trennte Unternehmer und Manager scharf aufgrund einer Feinklassification psychischer Dispositionen - hier insoweit methodisch ähnlich zu Knight. Psychische Dispositionen heißen bei Pareto "Residuen" (da sie sich einer ökonomischen Erklärung verschließen). Unternehmer sind durch die erste Klasse von Residuen gekennzeichnet, in der 
Elemente zusammengefaßt sind, die allesamt darauf hinauslaufen, daß die Bildung von Kombinationen von vorher nicht zusammengehörigen Einzelerscheinungen die besondere Fähigkeit der so Charakterisierten ausmacht, also Kombinationen von Ideen, Fakten, Sachverhalten etc., während die Manager eine zum Teil mit Risikoscheu gepaarte Beharrlichkeit (Residuum der Klasse II: Persistenz) kennzeichnet (Pareto 1935, § 2233; Samuels 1974, 67 ff.).

Diese Versuche, den Unternehmer in der ökonomischen Theorie zu bestimmen, sind sämtlich klassifikatorischer Art. Sie sind empirisch nur teils punktuell (Pareto 1935), teils systematisch im Wege von Einzelstudien (Redlich 1964) abgesichert, aber es kann nicht davon gesprochen werden, daß es sich um eine ökonomische Theorie im modernen empirisch positiv verstandenen Sinne handele. Erhärtete Hypothesen betreffen Entwicklungstendenzen, sind aber nicht ohne weiteres zum Beispiel ökonometrisch überprüfbar. Dies hängt mit den eingangs dargelegten methodischen Schwierigkeiten aufs engste zusammen. Dagegen bieten diese Ansätze Möglichkeiten des Verständnisses der Bestimmungsgründe für die Dynamik wirtschaftlicher - und gesellschaftlicher Abläufe. Im folgenden Abschnitt sollen diese Abläufe näher untersucht und einer verfahrenstheoretischen Interpretation unterzogen werden.

\section{Kombination und Informationsübertragung: eine verfahrenstheoretische Interpretation}

Die moderne Wirtschaftswissenschaft hat sich von einer Theorie des Marktes, zu der alsbald eine Theorie der plangesteuerten Ökonomie hinzutrat, allgemein zu einer Theorie der Entscheidungsverfahren zweckgerichtet handelnder Individuen entwickelt. Da Entscheidungen allemal Kommunikation voraussetzen, schließt dies eine (komperative) Theorie der Kommunikations- und Entscheidungsverfahren ein (Backhaus 1977). Im Mittelpunkt stehen solche Verfahren, deren Ergebnis über Allokation und Verteilung von Gütern entscheidet. Güter sind in allgemeiner Definition Handlungsalternativen, die Individuen positiv bewerten in dem Sinne, daß sie es vorziehen, über diese Handlungsalternativen zu verfügen im Gegensatz zu der Situation, in der ihnen diese Handlungsmöglichkeiten nicht offenstehen. Eigenartig an dieser Theorie ist freilich, daß sie zwar eine Theorie über Verfahren ist, daß Verfahren selbst aber nicht zum Gegenstand der Analyse gemacht werden. Damit soll gesagt werden, daß zwar die Struktur des Verfahrens, die Bedingungen seines Ablaufs etc. Gegenstand der Analyse sind, nicht aber der Ablauf des Verfahrens selbst. Diesen Zustand hat u.a Kirzner (1978) für die Markttheorie kritisiert und zum Ausgangspunkt seines Vorschlages gemacht, die Lücken durch die Einführung des Idealtyps "Unternehmer" auszufüllen. In Anlehnung an die durch Schumpeter und Pareto begründete Tradition, unter starker Einbeziehung vor allem aber auch des Schrifttums von Mises' erscheint der Unternehmer als Motor jener Abläufe, an deren Endpunkt die wirtschaftliche Neuerung steht. So erscheint der Unternehmer wieder als Motor des wirtschaftlichen Fortschritts.

Diese personalistische Sicht wird in letzter Zeit verstärkt kritisiert, zum Beispiel von Albach (1979). Er sieht - wie übrigens auch Schwödiauer (1980) nicht den Unternehmer, sondern die Unternehmung als Ort, an dem analystisch der Motor des Wandels festzumachen ist.

"Das moderne innovative Unternehmen weicht (...) in allen Punkten von dem Bild des dynamischen Unternehmers ab, das Schumpeter gezeichnet hat. Der Ruf nach dem "Schumpeter-Unternehmer" in der Wirtschaftspolitik ist daher sowohl auf nostalgische Verklärung der gesellschaftlichen 
Bedingungen des neunzehnten Jahrhunderts als auch auf mangelnde Kenntnis der Innovationsprozesse in der modernen Unternehmung zurückzuführen". Albach (1979, 547). Stattdessen gibt Albach sieben Bedingungen als Merkmale des innovativen Unternehmens an (S. $546 \mathrm{f}$.) und gelangt damit wiederum zur Beschreibung der Strukturen, in denen Innovationen stattfinden.

\section{Diese Bedingungen sind:}

Gegenüber dem personalistischen Ansatz der neu-österreichischen Schule hat Buchanan kritisch eingewandt, die Rolle des Unternehmers sei keineswegs stets eindeutig positiv aus ökonomischer Sicht bestimmbar. Buchanan unterscheidet den wahren und den neuen Unternehmer (new and true entrepeneur). Diese Unterscheidung kann für Wirtschaften im Umbruch besonders wichtig sein. Um den Unterschied zu demonstrieren, konstruiert Buchanan einen Fall, in dem die Regierung einmal Geldwertstabilität erhält, zum anderen nicht. Beide Unternehmer zeichnen sich nun dadurch aus, daß sie Gewinnchancen entdecken und realisieren. Der "wahre" Unternehmer tut dies in der gewohnten Weise, so daß nun eine neue wirtschaftliche Kombination erprobt wird, die sich alsdann als Verbesserung erweist. Der "neue" Unternehmer dagegen wird als eine Person charakterisiert, die die Wirkungen einer wirtschaftspolitischen Maßnahme der Regierung richtig antizipiert und daraus einen wirtschaftlichen Gewinn zieht. In dem von Buchanan diskutierten Fall wird eine Steigerung der Inflationsrate durch Spekulation mit Realwerten zur Einnahmequelle. Buchanan erkennt hier besorgt die Möglichkeit, daß bei Nichtidentität des "wahren" mit dem "neuen" Unternehmer sich die relativen Anreize zu Lasten des "wahren" und zugunsten des "neuen" Unternehmers verschoben haben. Während der "wahre" Unternehmer der Wirtschaft reale Wachstumspotentiale eröffnete, tut dies der "neue" Unternehmer nicht, der vielmehr bestimmte Schwachstellen der politischen Wirtschaftssteuerung eigenwirtschaftlich ausnutzt.

Die negative Beurteilung beruht aber darauf, daß ein neuer Akteur, die Regierung, eingeführt wurde, auf deren Verhalten der "neue" Unternehmer reagiert. Tatsächlich beruht das Beispiel auf der Interdependenz politischer und wirtschaftlicher Entscheidungsprozesse, die von einem Unternehmer genutzt wird. Durch politische Aktion werden wirtschaftliche Daten verändert. Auf diese Veränderung der Umstände reagiert der "neue" Unternehmer so, daß sich ein neues Gleichgewicht einstellt. Zur Beurteilung unter wirtschaftlichen Gesichtspunkten vergleiche man beide Fälle:

a) Die Regierung erhöht die Inflationsrate unbemerkt;

und

b) die Erhöhung der Inflationsrate wird vom "neuen" Unternehmer realisiert und entsprechend ausgenutzt.

Im ersten Fall herrscht beim Publikum Geldillusion aufgrund einer relativ zu hohen Bewertung der mittlerweile vermehrten (und daher im Wert gesunkenen) Geldbestände. Im zweiten Fall dagegen korrigiert der "neue" Unternehmer durch sein Verhalten die Preisverhältnisse zwischen Geld- und Realwerten. Die Spekulation des "neuen" Unternehmers führt dazu, daß die Preise der Realwerte entsprechend der Vermehrung der Geldmenge nach oben angepaßt werden, daß also das Austauschverhältnis zwischen Geld- und Realwerten wieder in Richtung auf das alte Austauschverhältnis hin angepaßt wird. Vorausgesetzt, das ursprüngliche Austauschverhältnis entsprach den Bewertungen der Wirtschaftssubjekte unter korrekter Einschätzung der verfügbaren 
Mengen, wird durch das Verhalten des "neuen" Unternehmers das "richtige" Austauschverhältnis wieder hergestellt. Diese unternehmerische Leistung ist volkswirtschaftlich wertvoll und begrenzt im übrigen die Wirksamkeit der von Buchanan kritisierten Regierungspolitik. Auch im Tranformationsprozeß spielt der "neue" Unternehmer eine wichtige Rolle, die je nach Standpunkt natürlich sehr unterschiedlich bewertet werden kann.

Der "neue" Unternehmer ist ein politischer Unternehmer in dem Sinne, daß er eine Brücke zwischen Wirtschaft und Politik schlägt. Die Ergebnisse der politischen Entscheidungen werden in ihrer Wirkung auf die Wirtschaft erkannt und der "neue", politische Unternehmer reagiert dem Funktionsprinzip der Wirtschaft entsprechend in der politisch-ökonomischen Interdependenz

EXKURS: Umsetzung von Wirtschaftstheorie in Wirtschaftspolitik

Auf einen Spezialfall politischen Unternehmertums sei hier eigens eingegangen, weil er in unmittelbarem Zusammenhang mit der Bewertung politischer Aktion durch die Wirtschaftstheorie und die Theorie der Wirtschaftspolitik steht. Diese Bewertung schließlich gab ja Buchanan Anlaß zu seiner negativen Einschätzung des "neuen" oder "politischen" Unternehmers. Buchanans Unternehmer war aufgrund seiner Brückenfunktion zwischen wirtschaftlichem und politischem Bereich wirksam. Einen anderen Fall des Überlappens politischer und wirtschaftlicher Prozesse beobachten wir dort, wo die Wirtschaftstheorie mit der Wirtschaftspolitik in Berührung gerät. Die Wirtschaftswissenschaft selbst läßt sich als ein kommunikatives System auffassen, dessen Ergebnisse unter Wettbewerbsbedingungen intern determiniert werden. Soweit sie empirisch ausgerichtet ist, reagiert die Wissenschaft als kommunikatives System auf die beobachtete Realität der Wirtschaft, die ihrerseits teilweise von der Wirtschaftspolitik gesteuert wird. Nun beruht die Chance einer wirkungsvollen Politiksteuerung auf der Kenntnis der wirtschaftlichen Abläufe und der Determinanten dieser Prozesse. Diese Kenntnis wird in der Wirtschaftswissenschaft hergestellt. Wissenschaftspolitische Unternehmer rezipieren diese Kenntnis und vermitteln sie wirtschaftspolitischen Akteuren, die sie ihrerseits umsetzen und das wirtschaftliche Gefüge dadurch verändern. Durch Rückkoppelung kann daraufhin wieder eine andere Wirtschaftstheorie, die entsprechend von wissenschaftspolitischen Unternehmern weitergetragen wird, entstehen, usw ${ }^{39}$.

Wiederum handelt es sich um einen Fall, in dem Unternehmer als Brücke zwischen kommunikativen Systemen Wandel erzeugen, einen Wandel, der sich unter dem Gesichtspunkt der Funktionenweise je eines einzelnen Systems nicht ohne weiteres einer Beurteilung erschließt. In diesem Fall ist zum Beispiel die Beurteilung der wirtschaftspolitischen Eingriffe einer demokratischen Regierung wirtschaftstheoretisch ebenso strittig wie die Beurteilung des Verhaltens der wissenschaftspolitischen Unternehmer unter dem Blickwinkel einer praktischen Wissenschaftstheorie oder Wissenschaftsethik. Unzweifelhaft ist aber, daß an Punkten des Überlappens kommunikativer Systeme Unternehmer Aktionschancen erkennen und Wandel zu erzeugen vermögen (Frey 1979).

Richard Portes wies in dem oben zitierten Jena Vortrag (1994) darauf hin, daß viele der Berater der Regierungen östlicher Wirtschaften im Umbruch vor allem Anglo-Amerikanischer Herkunft als Referenz ihre Beratererfahrung in Latein-Amerika gebrauchen; das heißt, hier wird der kategoriale Fehler gemacht, Wirtschaften im Umbruch mit solchen in der Entwicklung "bei im Prinzip gleichem Wirtschaftssystem" zu verwechseln. 
Dieser Fall des Beraters als Unternehmer zeigt deutlich, welche Rolle dem Unternehmer nicht nur in der Ökonomie, sondern allgemein in der Gesellschaft zukommt: Völlig im Einklang mit Leibensteins $(1968,73)$ Definition

"By N-entrepeneurship we mean the activities necessary to create or carry on an enterprise where not all the markets are well established or clearly defined and/or in which the relevant parts of the production function are not completely known. In both cases the entrepeneur co-ordinates activities that involve different markets; he is an intermarket operator. But in the case of Nentrepeneurship not all the markets exist or operate perfectly and the entrepeneur, if he is to be successful, must fill in for the market deficiencies." 40

erscheint uns der Unternehmer als tätiges Bindegleid zwischen zum Teil nur unvollkommen arbeitenden Verfahren. Dies gilt nicht nur für die Handlungen des Unternehmers in der Wirtschaft als Mittler zwischen verschiedenen Märkten; sondern allgemein für die Tätigkeit des politischen Unternehmers in der Gesellschaft. Hier verknüpft er in sich abgeschlossene Teilsegmente mit jeweils eigener Interaktion und wirkt damit sowohl als Brücke zwischen verschiedenen Verfahren als auch als Motor gesellschaftlichen Wandels.

\section{Gleichgewicht und Wohlfahrt}

In der politischen Ökonomie gehört die Vorstellung von einem zunächst wirtschaftlichen, dann aber auch politisch-sozialen Gleichgewicht zu den tragenden Konzeptionen. Solange nicht ein Gleichgewicht erreicht ist, ist damit zu rechnen, daß zum Teil sich gegenseitig bedingende sowie durch Aktion und Reaktion - erzeugende Anpassungsprozesse fortlaufen bis zu genau jenem Punkt, in dem wiederum ein Gleichgewichtszustand erreicht wird.

Die theoretische Schwierigkeit mit dieser Gleichgewichtskonzeption besteht darin, daß sie eine sowohl positiv-empirische als auch eine normative Interpretation besitzt ${ }^{41}$. Empirisch gesehen erfreuen sich die Teilnehmer an einem Verfahren, also etwa Akteure am Markt, Wettbewerber im politischen System etc. eines Nutzenmaximums in dem Sinne, daß eine Möglichkeit der Nutzensteigerung durch Bewegungen fort von diesem Gleichgewichtszustand unmöglich ist, ohne daß nicht einzelne, genauer mindestens ein anderer, Teilnehmer an dem Verfahren schlechter gestellt würden (Pareto 1971, VI § 33). Dieses Gleichgewicht bliebe im Prinzip auch erhalten, wenn sich nicht - und solange, wie sich nicht - Änderungen ergeben, die neue Bewegungen möglich machen. Diese Möglichkeit ist wiederum empirisch zu verstehen als die Chance, daß sich einzelne

Die Bezeichnung N-Unternehmer steht im Gegensatz zu R-Unternehmer; dies ist in Leibenstein's Terminologie die Unterscheidung zwischen Manager (R-Unternehmer) und Unternehmer (NUnternehmer).

41 Richard Portes zum Beispiel interpretiert in demselben Jena Vortrag Stabilität im Umbruchsprozess als positiven Wohlfahrtsindikator. Alternativ könnte man davon sprechen, die Apathie der erst und dann an Staatswirtschaften gewöhnten Bürger sei bedrohlich im Hinblick auf die Entwicklung von Freiheit, Demokratie und Marktwirtschaft, die Initiative, selbständiges Denken und Unternehmertum verlangen. Beide Interpretationen sind natürlich plakativ, und nur eine an Einzelheiten orientierte Analyse wird zu einem deutlicheren Bild führen können. 
Mitglieder des betrachteten Systems - oder Teilnehmer an dem betrachteten Verfahren - durch Veränderung besserstellen können, ohne daß andere benachteiligt werden.

Es erscheint mir nun wesentlich festzuhalten, daß diese sich sozusagen praktisch von selbst realisierenden Möglichkeiten grundsätzlich zu unterscheiden sind von rein hypothetischen Möglichkeiten. In den bisherigen Ausführungen war der Nutzenbegriff eine rein empirische Kategorie, der mehr das Ergebnis eines individuellen Kalküls über Wünschbares und Mögliches faßbar machte, statt Interessen und Chancen ihrer Durchsetzung. Statt Nutzen kann man Interesse lesen. Dieser Nutzenbegriff hat keinerlei normativen Gehalt. Denn es handelt sich um eine begrenzte Interessendokumentation. Aus der Sicht eines bestimmten Systems, etwa im Bereich der Wirtschaft, kann ein Nutzenmaximum - in Gestalt eines Interessenausgleichs, der zu einem Gleichgewicht geführt hat - erreicht sein, ohne daß, wenn man Kriterien aus anderen Verfahren, etwa die Ergebnisse politischer Abstimmungen, als Maßstab daran heranträgt, von einem Nutzen(oder Wohlfahrts-)Maximum gesprochen werden könnte (vergleiche im einzelnen Backhaus 1980b, II, III).

Folglich unterschied Pareto im Rahmen seiner Gleichgewichtsanalyse "tatsächliche" Bewegungen als Bewegungen fort vom Gleichgewicht, die in dem genannten Sinne zu einer Verbesserung führen, von "möglichen" Bewegungen, die zwar als Ergebnis und Konsens aus anderen kommunikativen Verfahren, etwa als politischer Entscheid, als wünschbare Verbesserung einer bestimmten Gleichgewichtssituation angegeben werden können, sich aber nicht in dem paretianischen Gleichgewichtssinne verwirklichen lassen, daß durch Kaldor/Hicks Bewegung niemand schlechter aber mindestens eine Person bessergestellt wird. Da nun über die Funktionsweise der Wirtschaft relativ viel, über die Funktionsweise anderer Prozesse dagegen relativ wenig bekannt ist, hielt es Pareto für richtig, sich zunächst auf das ökonomische Gleichgewicht zu beschränken (Pareto-Kriterium), auf die anderen Qualifikationen hinzuweisen, sie aber des weiteren nicht mehr zu beachten.

Diese Unterscheidung sei auf die Charakterisierung der Funktion des Unternehmers angewendet. Seine Funktion besteht darin, um noch einmal die Worte Leibensteins (1968) zu paraphrasieren, in unvollkommen funktionierenden Verfahren das Unvollkommene zu überwinden und voneinander getrennt ablaufende Verfahren miteinander zu verknüpfen, etwa verschiedene Teilmärkte oder auch verschiedene gesellschaftliche Sub-Systeme, etwa Politik und Wirtschaft. Auf den Märkten besteht die Funktion des erfolgreichen Unternehmers darin, bei Marktversagen durch eigene Organisationsleitung ein besseres Ergebnis zu erzielen. Hier kann illustrativ auf die Ausführungen Coases noch einmal verwiesen werden. Auf die unternehmerische Entscheidung geht schließlich die Gründung eines Unternehmens zurück, das dann entsteht, wenn an bestimmten Punkten Marktversagen (öffentliche Güter, externe Effekte, zunehmende Skalenerträge, usw.) auftritt und im Rahmen einer geeigneten Organisation, hier im Rahmen eines Unternehmens, behoben werden kann, vorzugsweise so, daß der faktische Eigner der Organisation daraus einen Vorteil ziehen kann. Die Funktion des Unternehmers besteht also darin, den Kranz der tatsächlichen Bewegungsalternativen um weitere anzureichern, die aus dem Bereich des rein Möglichen und Vorstellbaren in den Bereich des im Rahmen dieses Verfahrens Faßbaren und Verwirklichbaren gerückt werden. Stellt sich in einem Verfahren das paretianische Gleichgewicht sozusagen von selbst ein, so geschieht hier etwas neues: die von Unternehmern verwirklichten Lösungen sind solche, die sich nicht von selbst einstellen, weil sie zuvor nicht zum Kranz des Denkbaren, 
Möglichen und im Rahmen dieses Verfahrens Verwirklichbaren gezählt wurden. So erweitert der Unternehmer durch seine unternehmerische Initiative den Möglichkeitsraum und er schafft auf diese Weise die Voraussetzung für stets weitere Nutzenverbesserungen. Die unternehmerische Initiative ist Voraussetzung für Wohlfahrtssteigerungen.

Auch hier begegnet uns übrigens wiederum das Paradoxon der Selbstzerstörung des unternehmerischen Tätigkeitsbereiches. So wie Verfahrensversagen durch eine bestimmte Organisation (etwa: Gründung einer Unternehmung) geheilt, neue Alternativen bekannt und mögliche Bewegungen zu tatsächlichen Bewegungen geworden sind, etabliert sich ein neues Gleichgewicht wiederum "von selbst". Der Unternehmer hat hier seine Aufgabe verwicklicht, es ist nun Aufgabe des Managers oder, in Schumpeters Terminologie: des "Wirts", die neugestalteten Möglichkeiten voll auszuschöpfen und an die Grenze der nunmehr neu gestalteten Möglichkeiten zu gehen.

Diese Ausführungen gingen davon aus, daß in einer Gesellschaft verschiedene Sub-Systeme verfahrensmäßig organisiert sind, in denen Entscheidungen getroffen werden, die über Allokation und Verteilung von "Gütern" (im ökonomischen Sinne von "Opportunitäten") befinden. Der Unternehmer ist die Person (oder Gruppe von Personen), die entweder in einzelnen Verfahren Verfahrensmängel überwindet, oder aber verschiedene, voneinander getrennt ablaufende Verfahren miteinander verknüpft. Diese Verknüpfung freilich bleibt nur partial und führt regelmäßig nicht zur völligen Integration der so verknüpften Verfahren. Das hat vor allen Dingen die Konsequenz, daß durch Verfahrensverknüpfung um neue, tatsächlich zu verwirklichende Alternativen angereicherte Teilverfahren ihrerseits nicht "von selbst" ein allgemeines, umfassendes gesellschaftliches Optimum (Optimum supremum) verwirklichen, sondern lediglich durch marginale Bewegungen fortentwickelte Teiloptima. Hier findet auch die Chance des Unternehmers, durch seine Initiative die Voraussetzung für Wohlfahrtsverbesserungen zu schaffen, ihre Grenze. Entscheidungen über allgemeine gesellschaftliche Optima können nur im Rahmen von konstitutionellen Entscheidungen getroffen werden, durch die jene Verfahren geschaffen werden, in denen sich Optima "von selbst" einstellen und deren Versagen und mangelnde Integration dann ihrerseits von Unternehmern partial und inkremental überwunden werden kann.

\section{Politische Unternehmer}

Einleitend waren politische Unternehmer als Bewegungselement des politischen Prozesses bezeichnet worden. Der politische Prozeß wird hier vor allem im Gegensatz zum Marktgeschehen definiert als all jenes interaktive Handeln, das wir im politischen Bereich beobachten können. Es ist also nicht nur von geregelten Abstimmungsverfahren, wie zum Beispiel Wahlen, die Rede, und wir beschränken uns auch nicht auf das Verhalten von bzw. in bestimmten zuvor ausgewählten und abgegrenzten Institutionen. Dann müßten wir nämlich befürchten, definitorisch etwas ausgeschlossen zu haben, das sich später als der Ort erweist, an dem die Dynamik politischer Abläufe erzeugt wird.

In der Volkswirtschaftslehre ist es üblich, den politischen Prozeß dichotomisch dem Marktprozeß gegenüberzustellen. Während der Marktprozeß die Allokation privater Güter regelt, wird der politische Prozeß als ein analoges Verfahren geschildert, das über die Allokation öffentlicher Güter entscheidet. Öffentliche Güter sind bekanntlich jene, die die angenehme Eigenschaft haben, daß 
ihr Konsum durch einen Bürger den gleichzeitigen Konsum durch einen anderen nicht ausschließt. Diese Eigenschaft hat aber noch eine unangenehme Kehrseite. In großen Gruppen, in denen die einzelnen Gruppenmitglieder einander nicht persönlich bekannt sind und sich auch nicht an ihre Pflichten gegeneinander erinnern können, ist es nicht immer sicher, daß öffentliche Güter in ausreichender Menge oder überhaupt bereitgestellt werden. In der Regel ist es so, daß, wenn der Konsum durch einen Bürger den Konsum durch einen anderen nicht ausschließt, der andere von diesem Konsum auch nicht ausgeschlossen werden kann. Das hat aber zur Folge, daß sich jeder Bürger die Frage vorlegen wird, ob er seinen Anteil an den Kosten der Bereitstellung des öffentlichen Gutes tragen will. Schließlich kann er auch dann konsumieren, wenn er seinen Beitrag nicht bezahlt hat, da er - wie angenommen - vom Konsum nicht ausgeschlossen werden kann. Auf diesem Zusammenhang beruht Olsons (1965) Überlegung, daß es in großen Gruppen zum Angebot öffentlicher Güter nur dann kommen wird, wenn man entweder die einzelnen Gruppenmitglieder zu ihrem Beitrag zwingen kann oder aber die Mitgliedschaft in einer Organisation, die das öffentliche Gut bereitstellt, durch den Verkauf spezieller privater Güter oder Dienstleistungen an die Mitglieder sichergestellt wird, aus deren Erlösen dann die Produktion des öffentlichen Gutes finanziert wird. Man kann sagen, daß diese Analyse und die darauf gründende Beurteilung von der Mehrzahl der interessierten Wissenschaftler geteilt wird. Sie liefert unter anderem die Begründung für so unterschiedliche Institutionen wie das staatliche Steuerprivileg oder das Closed Shop-System, das die Gewerkschaftsmitgliedschaft in einem bestimmten Betrieb zur Regel macht, weil - und solange - diejenigen Arbeitnehmer, die nicht Gewerkschaftsmitglieder sind, von den gewerkschaftlich ausgehandelten Lohnsteigerungen, einem öffentlichen Gut für die gesamte Gruppe, nicht ausgeschlossen werden können.

Diese Analyse beruht auf der - in der Regel nicht besonders ausgeführten - Vorstellung, eine bestimmte Aktivität finde gleichsam im unstrukturierten politischen Raum statt und es bedürfe zur Organisation der Bereitstellung eines bestimmten öffentlichen Gutes zunächst einer Organisationsleistung so, daß die Gruppe der Nutznießer zusammengefaßt werden müsse. Da dies insbesondere für große (latente) Gruppen schwierig sei, unterbleibe auch deren Organisation mit der Folge ihrer Unterversorgung mit öffentlichen Gütern; so die Analyse Olsons (1965). Ähnliche Vorstellungen wiederholen sich allenthalben in der Literatur, etwa bei Frohlich, Oppenheimer und Young (1971) oder Eschenburg (1965). Dies ist umso erstaunlicher, als sich die beiden letztgenannten Arbeiten gerade mit dem Aspekt der Bereitstellung öffentlicher Güter durch einen politischen Unternehmer beschäftigen. Bei Frohlich, Oppenheimer und Young wird dies so dargestellt, als errichte der politische Unternehmer eine Organisation, und mit Hilfe dieser Organisation das erstrebte Ziel der Bereitstellung eines öffentlichen Gutes zu verwirklichen. Im Laufe der Analyse wird dann freilich die Organisation selbst wichtiger als der Unternehmer, von dem uns verschiedene Typen erscheinen (1971, 46 ff.), deren Charakteristika sich in der Kostenfunktion der Unternehmung in einem Verhaltensausdruck (the behavioral term b) niederschlagen, dessen Wert im wesentlichen die Dynamik (aber auch Risikonähe) des Managers der Unternehmung bezeichnet. Bei Rolf Eschenburg (1975) geht es zunächst um die Suche nach einem "Koordinations - Mechanismus für das Problem der gemeinsamen Produktion öffentlicher Güter" (286, meine Hervorhebung), also wiederum eine Organisation, die von einem "politischen Unternehmer" als initiativem Organisator $(1975,289)$ instituiert wird. Der Unternehmer ist auch hier der Schöpfer einer Organisation, eines politischen Unternehmens, in dem die Bereitstellung eines öffentlichen Gutes organisiert wird.

Das Anreiz-Beitragsproblem wird in dieser Organisation durchaus im Rahmen der Olsonschen 
Bedingungen gelöst, die verlangten, daß entweder ein einzelnes Mitglied zum Beitrag gezwungen werden müsse oder aber durch Kauf eines privaten Gutes zur Produktion des öffentlichen beitragen. Frohlich, Oppenheimer und Young (1971) formulieren auf dieser Basis ein politisches Organisationsmodell, das zudem noch freiwillige Leistungen einschließt. Dann gibt es offensichtlich einen trade off zwischen dem Dringen auf freiwillige Leistungen und Anwendung von - auf Gebühren gerichtetem - Zwang bei der Optimierung des Einsatzes des Lock-Droh-Potentials. Im Grundsatz ist die Analyse aber die gleiche. Sie bleibt auf Organisationen (Unternehmen) gerichtet, die der Bereitstellung öffentlicher Güter dienen.

Die Frage, die wir uns eingangs vorgelegt hatten, lautete aber nach den Bestimmungsgründen des Wachstums von Organisationen im politischen Sektor, dessen Zeuge wir in den letzten Jahren zunehmend geworden sind. Wo sind die dynamischen Elemente, die dieses Wachstum erzeugen? Es fällt uns schwer zu glauben, eine Vielfalt neuer Organisationsformen könne das Wachstum bewirkt haben.

Einen Lösungshinweis finden wir wieder bei Schumpeter (1946, XII), der in seiner "anderen Demokratietheorie" darauf hinwies, daß politische Unternehmer, eine bestimmte Idee verwirklichend, ein Problem schaffen, und mit diesem Programm eine Organisation, Unternehmung oder Partei übernehmen; daß ihnen diese Organisation gleichsam zufällt, wenn - und nachdem dem Unternehmer mit seinem Programm Erfolg zuteil geworden ist (1946, 276 ff., mit Beispielen aus der politischen Geschichte des ausgehenden 19. Jahrhunderts). Hier setzte auch Richard E. Wagner in seiner Kritik an Mancur Olsons_Logik des kollektiven Handelns an. Er schlug folgendes Gedankenexperiment vor.

Vorausgesetzt, jede Bereitstellung eines öffentlichen Gutes erfolge über die Organisation einer bestimmten Gruppe, einer Interessengruppe. Was geschieht, wenn diese fortfällt? Nach einem gesetzlichen Verbot solcher Gruppen müßten wir einen merklichen Unterschied feststellen. Insbesondere breite Gruppen mit Organisationsnachteil erleiden - so müssen wir beobachten - eine relative Unterversorgung mit öffentlichen Gütern. Ist dieses Ergebnis wahrscheinlich? Im Gegenteil: Es ist damit zu rechnen, daß politische Unternehmer in die Bresche springen. Diese Erwartung ergibt sich aus der Beobachtung, daß es große Gruppen gibt, die, obwohl nicht oder nur schwach organisiert, gleichwohl beträchtliche öffentliche Güter auf sich vereinigen. Wie ist dies möglich?

Um dies zu erklären, ist es sinnvoll, wieder an die Ausführungen über den Unternehmer in der ökonomischen Theorie anzuknüpfen. Dort war es unter anderem darum gegangen darauf hinzuweisen, daß der Unternehmer nicht unbedingt in einem von ihm gegründeten, oder von ihm betriebenen Unternehmen tätig sein muß. Es ist durchaus denkbar und auch nicht selten, daß ein Unternehmer außerhalb eines Unternehmens tätig ist, und nur ihm zu Gebote stehende Mittel dazu einsetzt, Neues zu strukturieren und Wandel zu gestalten. Eine Sicht, die den Unternehmer mit der Organisation der Unternehmung verschmelzt, verstellt den Blick auf das eigentlich wesentliche Element des Dynamischen, des Wandels.

Was für die ökonomische Theorie galt, gilt ebenso für die Politik. Auch hier sind Unternehmer tätig, die in Institutionen wirken, die lange vor ihnen schon bestanden haben. Abgeordnete schaffen nicht einen besonderen Wahlkreis, Ausschußvorsitzende sind nicht Väter der Idee, diese Ausschüsse zu gründen, Oppositionsführer verfügen über Einfluß mehr trotz als wegen ihrer Rolle 
als Chef einer bestimmten Organisation, Kandidaten müssen noch nicht einmal aufgestellt sein, um bereits politisch zu wirken, oder bei Erfolg können sie gleichwohl systematisch von der Regierungsverantwortung ferngehalten werden, ohne deshalb ihren Einfluß einbüßen zu müssen. Weniger nicht-wettbewerbliche Prozesse, die mit Drohung und Zwangarbeiten, als wettbewerbliche Prozesse sind es, die in Wirtschaft wie Politik politischen Unternehmern die Möglichkeit geben, Wandel zu erzeugen (Wagner 1966, 165).

Diese wettbewerblichen Prozesse halten in der Politik wie in der Wirtschaft Prämien bereit, in der Politik den politischen Profit. Der politische Profit besteht in Stimmen, die den Zugang zu Ämtern gewähren, die ihrerseits Einfluß eröffnen, der zu weiteren politisch gestaltenden Maßnahmen verwendet werden kann. Es ist, worauf ursprünglich Schumpeter (1946, XII) hinwies, ein Charakteristikum der Demokratie als politischer Organisationsform, daß sie einen Wettbewerbsprozeß organisiert, der zur Auslese Einzelner führt, die dann für die Menge entscheiden. Dieser Prozeß selbst enthält kein Element des Zwangs, Stimmen werden weder durch Zwang noch durch Drohung - regelmäßig - angezogen.

Die Chance der Besteuerung, die natürlich in einem technischen Sinne mit der Möglichkeit der Bereitstellung öffentlicher Güter unzertrennlich verknüpft ist, hat mit diesem Prozeß zunächst wenig zu tun, da in jenem Fall die repräsentative Entscheidung für ein Kollektiv dem politischen Unternehmer Gestaltungsräume eröffnet, die er gemäß seinen eigenen Absichten nutzen kann. Er kann dies im Rahmen der Institutionen, die er vorfindet und denen er den einen oder anderen Wandel hinzufügen mag, durchaus in unterschiedlicher Weise tun, nicht jede Bereitstellung eines öffentlichen Gutes verlangt nach der Erhebung von Steuern. In einer heterogenen Gesellschaft kann die Bereitstellung eines öffentlichen Gutes für eine Gruppe genau das Gegenteil für eine andere sein. Ein der zweiten Gruppe verpflichteter politischer Unternehmer stellt für seine Wählerschaft ein öffentliches Gut bereit, wenn er die Bereitstellung des öffentlichen Gutes für die erste Gruppe verhindert. Offensichtlich müssen in diesem Fall keine weiteren Steuern erhoben worden, sondern allenfalls welche eingespart. Auch dies ist nicht notwendig.

In modernen Industriegesellschaften erschöpft sich Staatlichkeit keineswegs mehr im Privileg der Besteuerung. Quasi-Besteuerung nimmt einen immer weiteren Raum ein. Aus öffentlichen Ämtern heraus kann man Auflagen machen oder mildern, Genehmigungen erteilen oder verweigern, Anträgen stattgeben oder sie verwerfen, in Vorgesprächen Anträge verändern. Verwaltungsgeschäfte (sogar in den Privatbereich hinein) verlagern und dafür Vergünstigungen gewähren, Projekte lancieren, initiieren und fördern, auch ohne in ihnen selbst aufzutreten, Projekte verhindern, verändern oder vernichten, ohne sich von einer wie auch immer gestalteten Öffentlichkeit rechtfertigen zu müssen. Betrifft dies den Mikrobereich zwischen Markt und Staat, so kann der politische Unternehmer auch an den Hebeln der Wirtschaftspolitik unternehmerisch tätig sein, Steuervergünstigungen für bestimmte Gruppen (definiert über absetzbare Tätigkeiten) gewähren durch Steuern, Gebühren, Marktordnungen und Zölle, politische Gruppen fördern oder benachteiligen, eine auf Beschäftigung gerichtete Politik - global im Hinblick auf abgrenzbare Großgruppen mit Teilorganisation - oder sektoral oder gar (wahl)bezirksweise betreiben, oder eine auf Geldwertstabilität gerichtete Politik durchsetzen, den Außenhandel industriebezogen oder bürokratiebezogen als Export- oder Entwicklungspolitik fördern oder behindern etc.

In allen diesen Beispielen kommt es nicht darauf an, zur Bereitstellung eines öffentlichen Gutes eine Organisation zu gründen, sondern es kommt darauf an, neue Formen, das heißt Programme 
zu (er)finden, unter deren Schirm die Begünstigungen als öffentliche Güter möglich sind. Je größer die Vielfalt dieser politisch-ökonomischen Möglichkeiten, desto größer ist auch der Anteil des politischen Elements in der rein wirtschaftlichen Kalkulation; das heißt desto größer ist auch für die rein wirtschaftlich orientierte Unternehmung die Bedeutung der auf Politik gerichteten Aktion; und desto größer ist die Chance des politischen Unternehmers, wirtschaftliche Chancen und politische Möglichkeiten in neuen Gestaltungsformen zu verknüpfen und zu nutzen.

\section{Der Wirtschaftsstil}

Der Wirtschaftsstil ist ein Konzept der wirtschaftlichen Staatswissenschaften, das seit dem Zerfall der Einheit der Gesellschaftswissenschaften und der zunehmenden Spezialisierung der Volkswirtschaftslehre etwas aus der Mode gekommen ist. Augenblicklich wird er eigentlich nur immer wieder von Bertram Schefold ins Spiel gebracht. Schefold unterläßt den Hinweis auf Sombart, der bei Spiethoff zentral ist ${ }^{42}$.

Die deutlichste Auseinandersetzung mit dem Konzept des Wirtschaftsstils finden wir nach wie vor bei Spiethoff (1933), und diese soll deshalb auch im Wortlaut zitiert werden: "Gehen wir zur Merkmalsbestimmung der Stile über, so ist kein Wort darüber zu verlieren, daß das bei weitem vollkommenste Unternehmen das von Sombart ist, auf dem allein weiter gebaut werden kann. In welcher Richtung soll das geschehen?

Erstens. Die Merkmale des Systems sind durch die Grundauffassung bestimmt, daß die "den Begriff der Wirtschaft bildenden Grundbestandteile" seien: die Wirtschaftsgesinnung, die Ordnung und die Technik. Weiter ist es nicht bedeutungslos, daß neben den Systemen" die Ordnung des Wirtschaftslebens noch von zwei anderen Seiten her umschrieben" wird. Hierdurch sind die Systeme grundsätzlich umrissen. Es dürfte aber notwendig sein, diesen Kreis zu durchbrechen. Deshalb ist es nicht Willkür oder Ausfluß einer billigen Neuerungssucht, wenn wir nicht von Wirtschaftssystemen, sondern von Wirtschaftsstilen sprechen und nicht einzelne Systeme, sondern Stile unterscheiden.

Zweitens. In mancher Beziehung hat Sombart wertvolles Erbgut unterbewertet und beiseite gelassen.

Drittens. Manche seiner Erkenntnisse könnten vielleicht noch geschickter merkmalsmäßig gefaßt werden.

Die Knappheit des zur Verfügung stehenden Raums macht die notwendig umfangreiche Begründung der Einzelheiten an dieser Stelle unmöglich. Es kann nur kurz das Ergebnis mitgeteilt werden.

I. Wirtschaftsgeist:

1. Sittliche Zweckeinstellung. Das Reich Gottes wird erstrebt; wirtschaftliche Erfolge werden erstrebt als Zeichen göttlicher Erwählung; die Belange der Allgemeinheit werden als Richtschnur

Vergleiche zum Beispiel Bertram Schefold vom Energiesystem zum Wirtschaftsstil in K.M.

Meyer Abich, Bertram Schefold, Wie möchten wir in Zukunft leben, der harte und der sanfte

Weg, München: Beck, 1981 S. 105 - 132 
genommen; das höchste irdische Glück der einzelnen wird erstrebt.

2. Die seelischen Antriebe zum wirtschaftlichen Handeln: Furcht vor Strafe, religiös-sittliche Beweggründe (Nächstenliebe, Pflichtgefühl, Trieb zum sittlichen Handeln), teilweise sittliche Beweggründe (Ehrgefühl, Drang zur Betätigung, Freude an der Arbeit), selbstischer Beweggrund (Streben nach dem eigenen wirtschaftlichen Vorteil), Persönlichkeitsdrang und Machtstreben. Verfolgt wird je nach der Stärke des Antriebes ein Nahrungs- oder ein Erwerbsziel.

3. Die geistige Einstellung. Gewohnheitsmäßige oder neuernde Einstellung, daraus folgend Verschiedenartigkeit der Technik.

II. Natürliche und technische Grundlagen:

4. Bevölkerungsdichte.

5. Natürliche Bevölkerungsbewegung. Stillstehend, langsam, mäßig, schnell wachsend.

6. Güterherstellung ohne und mit Arbeitsteilung.

7. Geistige und Handarbeit vereint oder geteilt.

8. Organische oder anorganisch-mechanische Durchführung der Technik.

III. Gesellschaftsverfassung:

9. Die Größe des wirtschaftlichen Gesellschaftskreises.

10. Das gesellschaftliche Verbundensein. Blutzusammenhang, Zwang, Vertrag.

11. Die gesellschaftliche Arbeitsteilung und die gesellschaftliche Zusammensetzung.

IV. Wirtschaftsverfassung:

12. Eigentumsverfassung. Für Erzeugungsgüter, bei freiem Eigentum an Genußgütern, entweder freies oder Staats- oder gesellschaftliches Eigentum. Für Genußgüter (und Erzeugungsgüter) gesellschaftliches Eigentum.

13. Verfassung der Gütererzeugung. Bedarfsdeckungswirtschaft: Erzeugung des Bedarfes unter einheitlicher Leitung. Geregelte Markterzeugung: Gütererzeugung in Selbstwirtschaften unter Regelung der Erzeugung und der Preisbildung durch gesellschaftliche Organe aus Unternehmern, Arbeitern, Verbrauchern bestehend (Planwirtschaft), oder durch politische Organe, Freie Markterzeugung: Gütererzeugung in Selbstwirtschaften frei nach der Marktlage.

14. Verteilungsverfassung. Allgemeines Entgelt, geregeltes besonderes Entgelt, freies besonderes Entgelt, Nächstenliebe.

15. Arbeitsverfassung. Genossenschaftlich, zwangsweise oder vertraglich herrschaftlich. Je nach der Verbindung dieser Möglichkeiten unter Nr. 12 bis 15 stellt sich die gesamte Wirtschaftsverfassung dar als: planvolle Leitung, oder als geregelte freie Verfassung, oder als freie Verfassung.

V. Wirtschaftslauf:

16. Der Wirtschaftslauf. Ständige Wirtschaft, fortschreitende Wirtschaft, Wirtschaftsablauf im Wechsel von Aufschwung und Stockung."

Nach Sombart und Spiethoff haben auch andere Volkswirte mit dem Begriff des Stils gearbeitet. Zu nennen sind Eduard Heimann, Hans Ritschl, in gewissem Sinne selbst Heinrich von Stackelberg, und insbesondere nach dem Kriege Gerhard Weisser und Alfred Müller- Armack, der, was bereits bei Sombart angelegt war, betonte daß "Wirtschaftsstile häufig auch von Glaubensüberzeugungen 
der Wirtschaftssubjekte geprägt werden."43 Eindrucksvoll ist die noch heute gültige Breite des Fächers, kein genanntes Kriterium ist heute unbedeutend. Hinzugetreten sind sicherlich nach den Marktreformen und der sozialen Marktwirtschaft die Sozialverfassung sowie die davon gar nicht wegzudenkende Steuerverfassung. Außerdem wird man im Hinblick auf die Einbindung einzelner Wirtschaftssysteme in größere Zusammenhänge, zum Beispiel in Zusammenhang mit der europäischen Einigung, die internationale vertragliche Einbindung eines Landes nicht außer Betracht lassen wollen, auch deshalb, weil internationale Verträge wie die Konvention über Menschenrechte bis tief in den Alltag hineinwirken. So ergeben sich statt der sechzehn Aspekte des Wirtschaftsstils, so wie wir sie bei Spiethoff gefunden haben, nunmehr deren neunzehn.

\section{Der neue Osten}

Diese neunzehn Stilelemente sind nun:

1. Sittliche Werte

2. Seelische Antriebe

3. Geistige Einstellung

4. Bevölkerungsdichte

5. Bevölkerungsbewegung

6. Arbeitsteilung

7. Geistige und Handarbeit

8. Organische/anorganische Durchführung der Technik

9. Größe des wirtschaftlichen Gesellschaftskreises

10. Gesellschaftliches Verbundensein: Blut, Zwang, Vertrag

11. Gesellschaftliche Arbeitsteilung

12. Eigentumsverfassung

13. Verfassung der Gütererzeugung

14. Verteilungsverfassung

15. Arbeitsverfassung

16. Wirtschaftslauf

17. Sozialverfassung

18. Steuerverfassung

19. Internationale Verankerung in Bündnissen und Vertragswerken

In den ehemahls zentralverwalteten Ländern Mittel- und Osteuropas ${ }^{44}$ spielen sich Transformationsprozeße ab, die in einzelnen sehr unterschiedlich ablaufen, deren Richtung im Hinblick auf eine neue Wirtschaftsordnung sehr uneinheitlich ist und die sich im einzelnen einer mit den herkömmlichen Kernbegriffen arbeitenden wirtschaftlichen Analyse, die sich etwa am Sozialprodukt, der Arbeitslosigkeit, der Geldentwertung etc. orientiert, kaum erschliessen. Es soll sich nun zeigen, ob mit dem Stilbegriff interessante Einsichten gewonnen werden können. 


\section{Ordnung, Unternehmer und Stil}

Wenn wir uns vor Augen führen, daß viele jener Erfahrungen, die wir in den amtlichen Statistiken niedergeschlagen finden, mit den Erfahrungen der Menschen, die wirtschaftliche Entscheidungen treffen, nicht übereinstimmen so fragen wir uns, ob nicht andere Möglichkeiten bestehen, die wirtschaftlich wesentlichen Ereignisse aufzuzeichnen und der Analyse zugänglich zu machen. Diesem Zweck diente das Konzept des Wirtschaftsstils, das Spiethoff entwickelt hatte, da er das Sombartsche Systemkonzept als unzureichend ansah. Jenes hatte zuvor bereits Aufsehen erregt insofern als es als eine beinahe untheoretische Sammlung vielfältiger Eindrücke aufgefaßt worden war.

Dieser Absatz ist nun ganz und gar dem Zweck gewidmet, das Stilkonzept zu erproben in der Absicht, mit den verschiedenen Facetten ein Bild zu zeichnen, das dem wirtschaftspolitisch interessierten Beobachter einen anderen Eindruck vermittelt als jenes, das allein aufgrund von amtlichen Statistiken erstellt worden ist.

Ich gehe deshalb von den Spiethoffschen Stilcharakteristica aus, und prüfe diese im Hinblick auf ihre Relevanz jeweils anhand eines Beispiels. Kritisch kann eingewandt werden, daß ein Beispiel nicht genüge; es handelt sich aber um einen illustrativen Versuch. Außerdem kann kritisch eingewandt werden, daß die pauschale Kritik an den amtlichen Statistiken unbegründet sei. Ein Kollege hat mir vorgehalten: geben Sie mir doch eine Handlungsanweisung, die anders ausfallen würde, wenn ich mich nicht auf die amtlichen Statistiken berufen würde, sondern auf Ihre stilistischen Eindrücke.

Diese Einwände sind ernst zu nehmen, aber sie sind auch in dem Sinne ungerechtfertigt, als die Stilelemente natürlich den statistischen Informationen zur Seite treten. Ist es nicht erstaunlich, möchte ich fragen, daß eine gewinnorientierte Unternehmung, Dow Jones Inc., die unter anderem das Wall Street Journal und das Wall Street Journal Europe betreibt, vor allem aber im chemischen Sektor tätig ist, doch einen von zwei Teilen Ihrer Publikation nicht den quantitativen sondern den qualitativen Informationen widmet, sogar den ersten?

Nun möchte ich den Leser einladen, den neunzehn Stilaspekten seine Aufmerksamkeit zu schenken.

1. Ein eindrucksvolles Beispiel für die Bedeutung sittlicher Werte im Transformationsprozeß wird immer wieder durch Alexander Solzhenitsyn gegeben, der nicht müde wird darauf hinzuweisen: ${ }^{45}$

"Having visited many of Russia's regions, having met with hundreds of people and having received thousands of letters' he said 'I have an impression our population is discouraged, that people are stupefied, in shock from their humiliation and shame because of their weakness. People doubt that the government's policy and reforms are in the interests of the people"'.

"He also repeated his criticism of the use of foreign currency in Russia and the purchase of foreign grain, and railed against the sale of farmland of any kind. Auction sales of land to the

45 Steven Erlanger, "Solzhenitsyn Speaks Out; but Russia's Deputies Shrug Him Off”, New York Times, p. 1, 1994 
nouveau riche means the sale of Russia itself, he said, sarcastically expressing doubt that a single of the 450 deputies 'is a peasant, actually growing grain'."

Solzhenitsyns Appell wird durch den Fall Kholodov unterstrichen. "According to Mr. Kholodov's editors, the reporter had been investigating illegal arms sales within the Western Army Group, the Red Army forces that completed their withdrawal from Germany last month. The editors said he had also uncovered a secret military training facility near the city of Ryazan, south of Moscow, where Russian special forces allegedly have been training mafia hit men in the art of murder. Mr. Kholodov's investigations led him directly to the top: to Matvei Burlakov, former commander in chief of the forces in Germany; to the GRU (military intelligence); and to Defense Minister Grachev."

2. Ungewöhnlicher unternehmerischer Drang bahnt sich oft im Transformationsprozeß an. Berlin bietet ein Beispiel, aber wir finden auch einen interessanten Fall für China, Frau Kader: ${ }^{46}$

"At the time, Beijing didn't permit private enterprise. Moreover, Muslim culture looks down on women working outside the home. So when Mrs. Kader was caught by authorities, "my husband was so ashamed, he asked me to leave, she says".

3. Die geistige Einstellung wandelt sich zur Betonung der Rechenhaftigkeit, wie es auch Sombart als Charakteristikum des modernen Kapitalismus (typischerweise in der Aufbruchsfase) hervorgehoben hat. Ein Ausschnit unter vielen kann dies illustrieren. ${ }^{47}$

"Alles soll kalkulierbar sein.

Die alten Bilder sind entwertet. Das über Jahrzehnte obligate und in stets gleichbleibend schlechter Druckqualität reproduzierte Bild von der Piketing line oder vom Arbeitslosen im Rinnstein ist, seit man weiß, daß es sie wirklich gibt, überflüssig geworden. "Wall Street", einmal der Inbegriff von Macht, taucht jetzt neben den Notierungen der Moskauer Börse auf. Die Shows, auf die man scharf war, solange man sie nicht zu sehen bekam, inszeniert man jetzt selber - bis man auch sie satt hat. Das russische Woodstock findet in Lushniki statt. Die neuen Moskauer Reichen machen Urlaub in Miami Beach, während der gewöhnliche Moskauer seinen Urlaub innerhalb der Grenzen seines Landes verbringt, das noch immer ein Kontinent für sich ist - wie der gewöhnliche Amerikaner auch.”

Einen Zusammenhang zwischen geistiger Einstellung und der Verfassung bestimmter Märkte (Geld, Waffen, Drogen) stellt Peter Handke in seinem, als literarisch zu wertenden Beitrag und als Serbien Essay bezeichneten Werk zur Diskussion. Er behauptet: ${ }^{48}$

"Vier Banditen ist es gelungen, der ganzen Welt die kriminellen Bedürfnisse einer Kaste als eine geostrategische Notwendigkeit unterzujubeln, die für den Frieden auf dem Planeten unerläßlich sei, und ein auf Verbrechen und Ausrottung gegründetes Ungleichgewicht als Stabilisierung einzuschmuggeln."

46 Kathy Chen, "Rags to Riches Story: How Rebiya Kader Made Her Fortune", The Wall Street Journal Europe, Thursday, September 22, 1994, p. 1

47 Karl Schlögel, "Die Yankees vom Arbat", Frankfurter Allgemeine Zeitung, Samstag, 24. September 1994

Dietmar Polaczek, "Geisterfahrer unter sich; Peter Handkes Serbien-Essay und Italiens Spaltungsangst", Frankfurter Allgemeine Zeitung, Samstag, 10. August 1996 
4. Bevölkerungsdichte in ländlichen Gebieten. Das Reproduktionsverhalten der Bevölkerung in Transformationsländern während des Transformationsprozesses kann die Vorhaltung von Infrastrukturleistungen seitens staatlicher Anbieter ernstlich in Frage stellen. Diese sekundäre Transformation kann ihrerseits neue Problemlagen erzeugen, für die eine Lösung nicht ohne weiteres im Bereich des Modellhaften liegt: ${ }^{49}$

"Manschnow, Germany - Willi Stellmacher is desperately seeking babies. For each infant born here, he pays the parents a bounty of 1,000 marks, or about $\$ 640$.

Mr. Stellmacher, the worried mayor of this village of 1,600 people near Germany's border with Poland, conceived of the baby-bonus program as a way of staving off local demographic disaster.

'Back in the 1980s, we had as many as 33 babies born each year,' he says. But since Communism fell in East Germany in 1989, Manschnow's baby tally has tumbled to as low as seven. There is no noticeable influx here of population from western Germany. Other villages have it even worse.

'A dead village'

The decline is imperiling the future of Manschnow's day-care center and school. 'And a village without those,' Mr. Stellmacher insists, 'is a dead village'.

At the moment, though, Manschnow doesn't look particularly sick. Indeed, the $\$ 260$ billion that Germany has pumped into eastern Germany is much in evidence here, and people generally are considerably more prosperous that they were under the communists. Outside Mr. Stellmacher's office, crews are paving dirt roads and laying sewer lines. Several houses are enjoying their first coats of paint in half a century, and new terra-cotta roofs shine in the summer sun.

The paradox of Manschnow is the paradox of eastern Germany, where the birthrate has slid 65\% since the summer of 1990. Babies are being born here now at an annual rate of five per thousand men, women and children in the population. That is less than a third the rate in the U.S."

5. Aus unterschiedlichen Gründen führt der Transformationsprozeß zu Bevölkerungsbewegungen in verschiedenen Ländern. Das Motiv der Kapitalerhaltung und Kapitalflucht ist ein Aspekt: ${ }^{50}$

"Happy Returns.

Russians are buying into some of Europe's richest and sexiest property markets, places where Russians haven't been seen in nearly 80 years. Real estate agents on Spain's Costa del Sol claim they've sold million-dollar villas and penthouse appartments to Russians eager for a place in the sun. Central London is another area where Russians lurk behind an increasing number of 'sold' signs. One international real-estate executive says they're buying up Cypres.

The real-estate world virtually buzzes with talk about Russians and the prospect of a new wave of super-rich clients to replace the exhausted fortunes of the Arabs, Japanese and Europe's old-line aristocracy. Hard numbers don't exist, but a sampling of real-estate agents, developers and lawyers around Europe turned up hundreds of Russian buyers in the last year or so - sometimes paying $\$ 1$ million or more. Thousands more have looked at homes, appartments, timesharers or even

Daniel Benjamin, "The Lack of Babies In a German Village Inspires a Bounty; Mayor of Manschnow Pays About \$640 per Newborn; Why Many Stay Childless", The Wall Street Journal Europe, Friday-Saturday, July 22-23, 1994, p. 1

Brian Coleman, "European Real Estate Marches Into New Era With Russian Invasion; Agents, Developers Compete For a Piece of the Action As Wealth Heads Abroad; One Lure: More Meat, Vodka", The Wall Street Journal Europe, Thursday, April 27, 1995, p. 1 
shops."

Ein anderer Grund liegt in dem Bestreben sicherer Humankapitalbildung: ${ }^{51}$

"Life can be rotten for rich kids in Russia, even with bananas. They can get roughed up at school. They can get kidnapped. They can get mixed up in crime. Some don't dare step out at night. So a few of their rich parents, who make lots of money one way or another, are sending them away from all that - to the warm, safe, civilized haven of a British boarding school."

6. Der Zusammenbruch der marktlichen Versorgung kann zur Rückkehr zur Selbstversorgungswirtschaft führen. Der natürliche Drang zu einer fortwährenden Entwicklung der Arbeitsteilung wird so gehemmt, oft zurückgeschraubt: ${ }^{52}$

"Yaroslavka, Ukraine - Feodor Adaminko long ago gave up believing that the state would ensure him a happy and secure retirement. So this year, the 52-year-old former subway worker decided to try an experiment at his dacha.

"My wife and I did real well with potatoes and such last year. So now I want to see if we can raise livestock. If the pig gets big enough, she should provide enough meat to get us through the winter," he says, perhaps a bit optimistically.

What gardens are to the British, dachas are to the Ukrainians. But while most Britons plow and furrow for the hoe of it, Ukrainians garden to survive."

7. Sanierungskonkurse gehören zu den Elementen geistiger Arbeit, die für einen erfolgreichen Transformationsprozeß unerläßlich sind. Ein Beispiel mag dies illustrieren: ${ }^{.53}$

"Belyaikovo, Russia - The only phone at the Zvezda cutlery factory has gone dead, leaving Aleksei Kuptsov puffing steam in the unheated main office.

'How can I work on marketing or anything else with this phone problem,' the 25-year-old plant boss grumbles.

The phone snafu is the least of Mr. Kuptsov's - or Zvezda's - problems. The trim, blond former engineering student has taken on the job of court-appointed director for the reorganization and management of the bankrupt factory. Since Russia passed a bankruptcy law in March, Zvezda is the country's first concern ever to undergo a Chapter 11-style proceeding, which in U.S. law protects a firm from creditors while allowing it to continue operating and work out debts.

Russian government officials hope Zvezda will become an example that helps break the taboo surrounding bankruptcy, thereby easing the way for thousands of such cases waiting in the wings. The issue is crucial because of the potential for mass unemployment and social unrest if companies simply go belly up.

'We wanted to show that it's possible, with good consultation, to build a program so the company

$51 \quad$ Barry Newman, "U.K. Boarding Schools Have a Distinct Charm To Well-Off Russians", The Wall Street Journal Europe, Wednesday, December 21, 1994, p. 1

$52 \quad$ Natalia A. Feduschak, “Tolstoy It's Not: The Plots Thicken With Potatoes, Pigs”, The Wall Street Journal Europe, Friday-Saturday, October 22-23, 1993, p. 1

53 Elisabeth Rubinfien, "Russian Plant Wrestles With Trials and Taboo Of Bankruptcy Process; Pilot Project Under New Law Lacks Credit and Markets; Workers Lack Conviction; A Touch of Soviet Idealism", The Wall Street Journal Europe, Thursday, November 4, 1993, p. 1 
gets another chance,' says Vasily Kozlov, deputy governor of Nizhny Novgorod, which selected Zvezda as a test case of the bankcruptcy law."

8. Erstaunlich viele handwerkliche Tätigkeiten erweisen sich als unerläßlich im Transformationsprozeß. Diese handwerklichen Tätigkeiten liegen nicht mehr im ursprünglichen handwerklichen Bereich. Es gibt eigentlich keinen Mangel an Schuhen, aber es gibt einen Mangel an Investitionsplänen, Marketingplänen und derartigen Produkten, die doch auf eine sehr handwerkliche Art und Weise erstellt werden können und werden: ${ }^{54}$

"Better Read than Red.

When Mr. Zotov and his colleagues came to Moscow State, the Soviet Union was still intact. The study of economics was a moribund exercise valued largely because it provided a path to Communist Party leadership. It focused nearly exclusively on Marxist texts. The freewheeling capitalism now emerging seemed unthinkable.

These days, Moscow State's economics department is flooded with applicants clamoring to get out of the sciences and into the equivalent of an MBA program. It accepted about 60 such transfers last year.

'When I entered school, my goal was to join the Communist Party elite, and I figured I'd need economics for that,' says Mr. Zotov. He had seen his father, a prominent physicist, sent to the fields to harvest potatoes. 'They never asked the party elite to do that,' he says.

Today, the party nomenclature is gone, but Mr. Zotov is still obsessed with power. A day earlier, he drew up three loan agreements totaling \$10 million, forwarding them to the bank's top officials for approval. 'The guys at the top make the decisions because they have more information,' he says. 'That's my biggest aspiration: to have access to that information.' Within 10 years, he predicts with quiet confidence, 'I'll be on the board."'

9. Die Größe des wirtschaftlichen Gesellschaftskreises kann von jener des politischen abweichen, diese Abweichung kann zu erheblichen Spannungen und Friktionen führen, selbst zu militärisch ausgetragenen Gegensätzen. Um den Auswüchsen des Transformationsprozesses entgegenzuwirken, fordert Alexander Solzjenitsin deshalb eine Stärkung der lokalen demokratischen Institutionen. Solzjenitsin plädiert für die Wiederbelebung der Institution Zemstvo, die im vorigen Jahrhundert bestand.

10. Gesellschaftliche Verbundenheit kann auch aufgrund einer auf Zwang beruhenden gemeinsamen Erfahrung wirksam werden. An diese Erlebniswelt knüpft ein ungewöhnliches Produkt an, das Gesellschaftsspiel "Ostalgie"..55

"Bonn - Your neighbour has joined the Communist Party, tricked and bribed his way into getting a phone and a Trabbi, and now is poised to reach the ultimate goal: Wandlitz, the leafy Berlin suburb where East Germany's party bosses resided in white villas far from the sorrows of the

$54 \quad$ Adi Ignatius, "In Capitalist Moscow, Young Business Grads Reap Money and Envy; Some Cast Aside Scruples In a Mad Dash to Cash In On Free-Market Reform; Masters of Russian Universe", The Wall Street Journal Europe, Monday, August 2, 1993, p. 1

$55 \quad$ Cacilie Rohwedder, “'Ostalgie' May Explain Why a Board Game Is a Hit in Germany; Sarcastic Look at Daily Life In Old Communist East Stirs Amusing Memories", The Wall Street Journal Europe, Monday, May 6, 1996 
masses.

That's when you reveal yourself to be a member of the state security apparatus - and send your neighbor straight to prison.

Such are the joys of a hot new board game in Germany. It's called Ueberholen ohne Einzuholen, which translates into 'Overtaking without catching up' - and that's just one of the historical jokes involved."

11. Auch die gesellschaftliche Arbeitsteilung unterliegt im Transformationsprozeß einem tiefgreifenden Wandel, der sich durchaus einer quantitativen Erfassung entziehen kann. ${ }^{56}$

"The country is supposed to be in a deep economic crises, but the traffic jams in Moscow get bigger and bigger,' a foreign diplomat commented sardonically.

Which is the 'real' Russia - that of the great depression or the emerging market?"

12. Ein wesentliches Problem bietet die Eigentumsverfassung. Für Rußland etwa wird berichtet: ${ }^{57}$

"The distance Russia has to go to develop a modern market economy is highlighted when one considers the common features that underlie the many different 'brands' of capitalism around the world.

One is a competitive price system; a second is a system of agreed-upon 'rules of the game'. The latter extend from general values, such as that the market should not be a corrupter, to specific laws and regulation. They also include norms - for instance, a dispute over a contract should not be settled by murder but by a court. And a market system is embedded in a legal, cultural, and institutional context that supports its workings.

By these criteria, Russia has a long way to go on the road to a mature market system.

This is what Russians mean when they say that what they have is 'a bazaar, not an economy'. A body of rules and laws is yet to be written. Even lawyers are in short supply and good independent judges are even more scarce. The concept or property, fundamental to a market system, is far from worked out."

Die unsichere Eigentumsverfassung in Rußland hat zu einer Kapitalflucht geführt, die den Entwicklungsprozeß unweigerlich hemmt: ${ }^{58}$

"Limassol, Cyprus - Many Russian business tycoons are worried about a Communist comeback in June's presidential election. But not Alexander V. Skorynin.

Once a prominent factory owner in the Volga River city of Saratov, Mr. Skorynin says he long ago grew disenchanted with Russia's high taxes, bureaucratic headaches and violent crimes against executives. So three years ago, he decided to follow thousands of other rich countrymen to Russian

$56 \quad$ Daniel Yergin and Thane Gustafson, "Let's Get Down to Business, Comrade”, Financial Times Weekend, July 9, 1994. pp. 1

57 Daniel Yergin and Thane Gustafson, "Let's Get Down to Business, Comrade”, Financial Times Weekend, July 9, 1994. pp. 1 and p. 10

$58 \quad$ Mark M. Nelson, "Russian Capitalists Use Cyprus as Springboard To Global Marketplace; Tycoons Flourish in a Haven From Political Uncertainty, High Taxes, Crime at Home; Mr. Skorynin Builds a Xanadu”, The Wall Street Journal Europe, Thursday, May 9, 1996 
capitalism's home away from home, the Mediterranean island of Cyprus. He now not only manages his Russian textile company from here, but publishes a Russian-language newspaper for his fellow exiles. And it is here that he is building his Xanady, a lavish mansion on a Cyprus hillside.

Russian expatriates like Mr. Skorynin are insuring themselves against the uncertain politics in their homeland. Using Cyprus as a place to manage their money and keep up their trade and business contacts with the rest of the world, these Russians operate a dynamic and growing economy free of many of the constraints that plague business people back home."

Andererseits zeigt die Erfahrung etwa in der Ukraine, daß selbst wenn eine dysfunctionale Eigentumsordnung oktroiert wird, sich eine alternative eventuell informelle Ordnung bilden kann: ${ }^{59}$

"Kiev, Ukraine - Forget about the dreary business statistics pouring out of Ukraine: The country is thriving, thanks to a vibrant underground economy.

In Kiev, kids in Reeboks dash through streets snarled with Jeeps and shiny Mercedes. Swanky convenience stores offer late-night snackers bottles of Dom Perignon at $\$ 140$ a pop.

This prosperity belies official statistics that show gross domestic product contracting by a belttightening 52\% since the break from Moscow in 1991. But factor in about $\$ 30$ billion a year, or what the World Bank estimates to be $48.9 \%$ or 1995 GDP, in unreported cash and the crisis looks much worse on paper that it is in reality.

To keep growth humming along and get their fiscal house in order, though, officials must get all this activity on the books. Last year, the government lost out on some $\$ 12$ billion in tax receipts, or a little less than its total 1996 budget.

'It's crucial that government create conditions that will allow businesses to operate in the open,' says Daniel Kaufmann, the World Bank's resident head of mission."

13. Die Verfassung der Gütererzeugung kann sich im Transformationsprozeß schnell ändern: ${ }^{60}$

"Most businesses this side of the Berlin Wall spent the past few decades specializing in the production of one thing: junk.

But now, more and more companies in Central and Eastern Europe, no longer content to make shoddy autos and second-rate textiles, are rapidly raising the quality of their products to Western standards. Their success suggests that these countries - especially Poland, Hungary and the Czech Republic - are rejoining the West more quickly than many people expected.

Their gains could serve as a warning to Western producers. Industry in Central and Eastern Europe, prodded by Western investors and competition from Western imports, is combining its old advantage of cheap labor with newly upgraded merchandise to pose a more serious export threat. The Czech Republic, for example, has increased exports to the West to $70 \%$ of total exports from $31 \%$ in $1989 . "$

14. Die Verteilungsverfassung im Transformationsprozeß stößt immer wieder auf Befremden. Die

$59 \quad$ Matthew Brzezinski, “Ukraine's Economy Is Thriving, But the Numbers Don't Tell Story", The Wall Street Journal, Monday, May 13, 1996

Dana Milbank, "East Europe's Industry Is Raising Its Quality And Taking On West; Swift Change in Work Habits Yields Exportable Goods While Costs Remain Low; A Halt to Drinking on the Job", The Wall Street Journal Europe, Thursday, September 22, 1994, p. 1 
folgende Beschreibung ist dafür typisch: ${ }^{61}$

"From Crisis to Fortune.

For Russia's bravest entrepreneurs, the country's crises amount to new ways to make a fortune. It isn't for the skittish; much of the fast money is in traditionally volatile markets like real estate, and some of these entrepreneurs could lose everything as quickly as they made it. Long-term investment is rare. Still, Russia's chaotic economy has created astonishing opportunities for instant wealth.

'I like a volatile market,' says Roman Miagkikh, a self-styled Russian financier and Mel Gibson lookalike who favors expensive Italian fashions. 'It creates an environment for superprofits.'

Mr. Nersesyan, casually stylish in Levis and a tweed jacket, raised a few eyebrows when he decided to plunge into the restaurant trade. For years, he had been a typical intellectual. Quietly dissatisfied with the Soviet system, he toiled in the literary world at a fixed state salary and did English translations on the side to earn pocket money.

When the system collapsed, Mr. Nersesyan watched as several friends launched primitive, but successful, business careers. With $\$ 30,000$ borrowed from friends and banks, he finally took the plunge himself last year.

Mr. Nersesya quickly learned to profit from the sorry condition of Russia's former state-run sector. He was able to pry prime space away from a grand turn-of-the-century theater that relied on subsidies and that now is in dire need of cash. Besides paying rent and utilities,

Mr. Nersesyan agreed to provide 50 free meals a day to the theater's cast - in return for a storefront space on Moscow's relatively upscale Tverskaya Street.

He didn't need to spend much to fix up the restaurant, either. For the requisite combination of Texan-Mexican ambience, he hired a construction crew - former Soviet rocket designers desperate for extra cash - to build a reasonably authentic swinging saloon door, and he had a Western pianobar tableau painted on the wall. He found some sombreros and put an oversize blow-up bottle of Mexico's Corona beer in the window.

'Business is like theater,' says Mr. Nersesyan, who also manages an international theatrical exchange program. 'You put in a few touches like the saloon door, and people think you must have spent a million dollars."”

15. Während mitbestimmte Aufsichtsräte in Deutschland darauf achten müssen, daß die Vorstände Gewinn erwirtschaften, kann das Entstehen von Gewinnen in der Arbeitswelt im Transformationsprozeß Probleme aufwerfen: ${ }^{62}$

"Soon after the Petrodvorets Watch Co. went private in 1990, a terrible thing happened: It started turning a profit.

While the notion is central to capitalism, it was so new and strange that workers and managers at this former state-owned watch factory started coming unwound.

Adi Ignatius, "Russia's Entrepreneurs Are Making Fortunes, Not Always Legally; They Open Mexican Cafes, Banks, Software Firms, While Fending Off Mob; Stashing Cash in Switzerland", The Wall Street Journal Europe, Tuesday, March 1, 1994, p. 1

Anita Raghavan, "Strangeness of Profit Brings Russian Factory A Time of Troubles; Watchmaker Makes Money But Ticks Off Its Workers; Overtime for the Shrinks; Marketing That 'Zero Hour'", The Wall Street Journal Europe, Wednesday, November 17, 1993, p. 1 
Squabbles broke out over how to use profits. Squabbles broke out over how much profit was actually necessary. Managers who managed for profits were accused of profiting from the misery of workers. Miffed, some lifetime employees wandered off into the free market to make watches for the competition. This drove managers crazy.

Fear of Succes.

Larisa Almiz, Petrodvorets's chief doctor, noticed a disturbing trend: Hundreds of employees were flocking to the factory clinic complaining of sleeplessness. Scores more were so distraught they suffered nervous breakdowns. Profit making was mandating a whole new way of thinking requiring sudden and radical change. 'People were scared,' says Dr. Almiz.

People still are, though they are getting used to profits and the change they bring. They have to; Petrodvorets seems destined for success."

16. Eine eigenartige Beziehung zwischen der Vervollständigung der europäischen Währungsunion stellt ein Beitrag in der New York Times mit dem Wirtschaftslauf in Mittel- und Osteuropa her. In dem Artikel wird behauptet, daß der Übergang zur Währungsunion weniger entwickelten Staaten in Mittel- und Osteuropa in eine chronische Rezession stürzen wird: ${ }^{63}$

"'If a monetary union is launched on schedule,' predicted Jan Krzysztof Bielecki, the former Prime Minister of Poland, 'it will touch off a chain reaction that will halt integration.'

This is not an entirely new thought, but it is particularly relevant as the deadline for locking together at least a handful of Europe's currencies nears. Economists of varying ideological stripe have long worried that the transition to monetary union may trap some less-advanced nations into chronic recession, much the way single currencies handcuffed efforts to develop Canada's Maritime Provinces and Italy's poor southern region."

17. Die Transformation verändert auch die Sozialverfassung tiefgreifend: ${ }^{64}$

"The workers of the state-owned Porcelana china factory went on strike in 1980 against the evils of communism and in favor of political liberation. In 1993, the workers of the privately owned Porcelana china factory went on strike against the evils of capitalism and in favor of women's liberation.

The first strike took a decade to show results. The second might take longer. Communism was no picnic, but it gave women standing at work and security at home.

Now they've got stress at work and strife at home. Poles are so aggrieved at how capitalism has been thrust on them that in September they voted the old order's descendants back into power. Polish women have reason to feel more aggrieved than most."

"Hard Choice.

So Mrs. Bartinowska has a choice: She can try to get by, and go back to work in a year. Or she can quit, get $\$ 75$ on the dole for 18 months, and lose her job for good. Her husband, a repairman, earns $\$ 160$ a month. Porcelana no longer pays for day care; that's \$35 a month. Mrs. Bartinowska would do better to work nights and care for the children herself during the day. 'I'm taking a risk,' she says. 'I hope I find a night job. Anyway, it's good to be with your child. I'm not saying that

63 Peter Passell, "Economic Scene; Central Europe is unsettled by a currency union for West Europe", The New York Times, May 16, 1996

Barry Newman, "Women in Poland Find Little Liberation In Shift to Democracy; Free Market Shears Them Of Jobs and Benefits; Abortions Are a No-No; Horror of the 'Plastic Bags'", The Wall Street Journal Europe, Tuesday, November 16, 1993, p. 1 
capitalism is bad. But in my case, it isn't working very well."”

18. Im Transformationsprozeß zählt die Steuerverfassung zu den Kernproblemen: ${ }^{65}$

"Wie überall in Rußland ist das sichtbarste Zeichen der Öffnung neben regelmäßigen Auftritten von Predigern amerikanischer Sekten die Flut von billigen Importwaren, die in jedem Geschäft die einheimische Produktion zu verdrängen drohen. Auf dem Hauptplatz der Stadt, wo die sowjetische Parteiführung einst Paraden abnahm, wurden die fest montierten kommunistischen Parolen einfach umfunktioniert zu Werbetafeln für die neuen Investmentfonds, die an die höchst bourgeoisen 'Ideale' von Auto und Eigenheim appellieren.

Wie überall im Land bewegt die neue Unternehmerklasse von Wolgograd vor allem die unerträgliche Steuerlast. Seit drei Jahren trete er auf der Stelle und könne sich nicht vergrößern, sagte Nikitin, weil der Fiskus neunzig Prozent seiner Gewinne abschöpft. Die Region zieht eine jeweils einprozentige Steuer ein für Straßenbau, Bildungswesen und Polizei, nach Moskau gehen Gewinn- und Eigentumssteuer. Besonders absurd erscheint es Nikitin, daß er seine Einnahmen auch vorausschätzen und im voraus versteuern muß; wenn er sich dabei irrt, muß er nicht nur die Differenz, sondern obendrein eine Strafe zahlen. Vom Eigentum werden nicht nur Immobilien und Kraftwagen versteuert, sondern auch Büromöbel, das Geld auf dem Konto und insbesondere Devisen, weil sie inflationsbeständiger sind als der Rubel."

19. Die internationale Einbindung in wirtschaftliche und politische Bündnisse ist eine weitere Quelle des Wandels, die den Aufbau der Institutionen einer Marktwirtschaft erlaubt: ${ }^{66}$

"A battle for influence is raging across the new market economies of Eastern Europe as the U.S. and Germany slug it out over corporate law, management principles and shareholders rights.

The contest pits continental Europe's Napoleonic civil-code traditions against the common law of the Anglo-Saxons; German banks against the big Anglo-American investment houses; Germany's conservative boardroom culture against America's rough-and-tumble capitalism of proxy fights, hostile takeovers and junk bonds. And while the battle isn't over, the Germans, who have exerted influence over Eastern Europe for many centuries, are often - but not always - ahead.

Take the former Soviet republic of Georgia. For months, a team of German experts headed by a Bremen University law professor and funded by the German government helped the Georgian draft commercial legislation much like Germany's. It would have made hostile takeovers almost impossible and allowed managers to all but ignore shareholders."

\section{Nutzen und Anwendungsmöglichkeiten einer ökonomischen Theorie der Ordnung, der politischen Unternehmer und der Wirtschaftsstile im Hinblick auf die Probleme der}

Kerstin Holm, "Für Unternehmer in Wolgograd ist Moskau ein gigantischer Parasit; Die Steuerlast/Wandel in der einstigen Stadt Stalins/Kommunistische Parolen zu Werbetafeln für Auto und Eigenheim", Frankfurter Allgemeine Zeitung, Samstag , 24. September 1994

Mark M. Nelson, "Two Styles of Business Vie in East Europe; Americans, Germans Have a Motive in Trying to Mold Laws", The Wall Street Journal, Monday, April 3, 1995 


\section{Transformationsökonomie}

Ich habe versucht, Grundzüge einer Antwort auf die eingangs gestellte Frage nach den dynamischen Ursachen des Strukturwandels, der in der Einleitung geschildert wurde, zu finden. Es wurde vorgeschlagen, den Blick dabei auf den politischen Unternehmer zu konzentrieren, der der Motor dieses Wandels ist. Außerdem ist das Umfeld des Unternehmens zu berücksichtigen, das mit der Wirtschaftsordnung und dem Wirtschaftsstil gekennzeichnet werden kann. Wie weit kann eine solche Theorie führen?

Einschränkend ist zu sagen, daß wir bislang nur über Elemente einer solchen Theorie verfügen. Auch in diesem Aufsatz habe ich sie nicht bis zu dem Punkt formuliert, an dem Hypothesen sich klar abzeichnen würden, die man alsdann empirisch mit modernen Methoden testen könnte. Dies ist in Teilbereichen aber möglich. Positiv dagegen scheint es zu Buche zu schlagen, daß eine Fülle von Einzelphänomenen, die man mit einer dem politisch-ökonomischen Wandel der letzten Jahrzehnte zugrundeliegenden Tendenz verknüpfen kann, mit dem Begriff des politischen Unternehmers neu organisiert und so zu einem verständnisleitenden Konzept zusammengefügt werden können. Mit dieser Arbeit stehe ich erst am Anfang. Aber ich hoffe, deutlich gemacht zu haben, daß der Unternehmer sowohl in der Wirtschaft als auch in der Politik eine genaue und bestimmbare Rolle spielt, daß diese Rolle im Rahmen der Institutionen, in denen sie gespielt wird, als dynamisch u n d im normativen Sinne wünschenswert zu bewerten ist in dem Sinne, daß auf Freiwilligkeit aller Beteiligten beruhende Bewegung zustandekommt, die zu partiellen Besserstellungen führt. Der Unternehmer kann neu gestalten stets nur im Rahmen einer bestehenden allgemeinen Ordnung, einer Verfassung; die Neugestaltungen sind - normativ gesprochen - stets nicht schlechter als die Verfassung, die sie zuläßt. Die Verfassung selbst freilich ist, obwohl dauerndem Wandel unterworfen, gegebenenfalls Gegenstand eines eigenständigen Beurteilungsprozesses.

Die gesamte Einschätzung der Rolle eines Unternehmers beruht auf einer Sicht, die ihn als das konstitutive Element kommunikativer Verfahren begreift. Derartige Verfahren sind sowohl der Markt, politische Prozesse, als auch andere Verfahren, in denen Entscheidungen zustande kommen. Diese Verfahren setzen sämtlich voraus, daß neue Ideen formuliert und in habhafte Programme umgesetzt werden. Dies ist die Rolle des Unternehmers, in der Wirtschaft wie in der Politik.

\section{Schluß}

Abschließend können wir meines Erachtens den Schluß ziehen, daß die Konzepte der Ordnung, des Unternehmers und des Stils in Ihrem Zusammenspiel sehr wohl eine aufschlußreiche Erklärung wirtschaftlicher Wandlungsvorgänge, z.B. jener in den Transformationsländern, erlauben, die auch der Wirtschaftspolitik zu Grunde gelegt werden können. Der Wandel umfaßt ja mehr als nur die Wirtschaft und stärker als im Tagesgeschäft der Wirtschaftspolitik kommt es auf die Schaffung einer Ordnung an, in der unternehmerisches Handeln möglich wird und auch gefördert. Darüberhinaus aber zeigt sich deutlich, daß nicht von einem Tranformationsprozeß die Rede sein kann. Sehr unterschiedliche Systeme unterliegen dem Wandel, und sie werden sich auch auf sehr unterschiedliche Systeme hin transformieren, die mit dem Stilbegriff sinnvoll beschrieben werden können, ohne daß die Kategorien zu holzschnittartig geraten. 


\section{LITERATURVERZEICHNIS}

Armen A. Alchian \& Harold Demsetz, "Production, Information Costs and Economic Organization". American Economic Review 62, 1972, pp 777-795

Horst Albach, "Zur Wiederentdeckung des Unternehmers in der wirtschaftspolitischen Diskussion". Zeitschrift für die gesamte Staatswissenschaft 135.4 1979, 535-552

Peter Badura, Fritz Rittner, Bernd Rüthers, Mitbestimmungsgesetz 1976 und Grundgesetz: Gemeinschaftsgutachten ("Kölner Gutachten"). München: Beck 1977

Jürgen Backhaus, "Efficient Statute Law". In: M. Faure and R. van den Bergh (eds.), Essays in Law and Economics: Corporations, Accident Prevention and Compensation for Losses, Antwerpen, Apeldoorn: Maklu, 1989 (S. 23-32).

Jürgen Backhaus, "Politische Ökonomie als Theorie der Begründung". Zeitschrift für allgemeine Wissenschaftstheorie VIII.1 1977, 91-117

Jürgen Backhaus, Öffentliche Unternehmen: Zum Wirtschaftsrecht, den Funktionen und Rechtsformen öffentlicher Unternhmen. Frankfurt: Haag und Herchen 1980 (2)

Jürgen Backhaus, “The Pareto Principle”. Analyse und Kritik 2, 1980, 146-171

Jürgen Backhaus, Ökonomik der Partizipativen Unternehmung I. (Mit einem Vorwort von Gérard Gäfgen). Tübingen: Mohr/Siebeck 1979

Brian Barry, Hayek's Social and Economic Philosophy. London: Macmillan, 1979

William J. Baumol, "Entrepeneurship in Economic Theory". American Economic Review, Papers \& Proceedings, 58.2, 1968, 64-71

William J. Baumol, Welfare Economics and the Theory of the State. London: Bell 1967.

Erwin von Beckerath, Einige Bemerkungen zu Schumpeters "Theorie der wirtschaftlichen Entwicklung". Schmollers Jahrbuch für Gesetzgebung, Verwaltung und Volkswirtschaft im Deutschen Reiche 53.II, 1929, pp 537-555

Herbert Biermann, Ansatzpunkte einer allgemeinen Strukturpolitik: Destabilisierung von Managementgremien und/oder Organisationen als Voraussetzung für Wettbewerb und Demokratie. Berlin: Duncker \& Humblot 1976 (Hrsg., Budgets and Bureaucrats: Borcherding, Thomas E., The Sources of Government Growth. Durham: NC, 1977)

James M. Buchanan, Resource Allocation and Entrepeneurship. Mimeograph, Blacksburg, Va 1979.

Bundesverfassungsgericht (Bverf GE) (1995) 
Ronald Coase, “The Nature of the Firm”. Economica 4, 1937, pp 386-405

Thomas C. Cochran, "Entrepeneurship". International Encyclopaedia of the Social Sciences, 5, pp 87-90, 1968

Arthur H. Cole, "The Entrepeneur: Introductory Remarks". American Economic Review, Papers \& Proceedings 58.2, 1968, pp 60-63

Erlanger, S., "Solzhenitsyn Speaks Out; but Russia's Deputies Shrug Him Off, in: New York Times, S. 1, 1994

Rolf Eschenburg, "Politische Unternehmer und öffentliche Güter: Möglichkeiten und Grenzen der gemeinsamen Bereitstellung öffentlicher Güter in Großgruppen", in: Wirtschaft und Gesellschaft: Ordnung ohne Dogma. Festschrift für Heinz-Dietrich Ortlieb. Erich Arndt, Wolfgang Michalski, Bruno Molitor (eds.) Tübingen: Mohr/Siebeck 1975, pp 257-302

Bruno S. Frey, "Models of Perfect Competition in Pure Democracy". Kyklos 23, 1970, 736-755

Bruno S. Frey, "Von der politischen Ökonomie zur Wirtschaftspolitik", pp. 789-808 in: Staat und Wirtschaft. Verhandlungen auf der Arbeitstagung des Vereins für Sozialpolitik - Gesellschaft für Wirtschafts- und Sozialwissenschaften in Hamburg, 1978. Berlin: Duncker \& Humblot 1979 (=Schriften des Vereins für Sozialpolitik - Gesellschaft für Wirtschafts- und Sozialwissenschaften NF. 102).

Norman Frohlich, Joe A. Oppenheimer, Oran R. Young, Political Leadership and Collective Goods. Princeton University Press 1971.

Gérard Gäfgen, "On the Methodology and Political Economy of Galbraithian Economics". Kyklos, 27.4, 1974, pp 705-731.

Gérard Gäfgen, Theorie der wirtschaftlichen Entscheidung. Tübingen: Mohr/Siebeck 1974.

John Kenneth Galbraith, The New Industrial State. Boston: Houghton 1967.

John Kenneth Galbraith, The Affluent Society. Boston: Houghton 1958.

Johannes Gerhardt, Unternehmertum und Wirtschaftsführung. Tübingen: Mohr/Siebeck 1930

John Hicks, Value and Capital. Oxford: University Press 1939

Friedrich August von Hayek, "The Use of Knowledge in Society." American Economic Review, 35, 1945, S. 519-530

Friedrich A. von Hayek, "The Non Sequitur of the Dependence Effect." In idem, Studies in Philosophy, Politics and Economics. New Haven: Yale University Press, 1967

Friedrich von Hayek, Law, Legislation, and Liberty: A New Statement of the Liberal Principles 
of Justice and Political Economy 1, "Rules and Orders". Chicago: The University of Chicago Press 1973

Friedrich von Hayek, Law, Legislation, and Liberty: A New Statement of the Liberal Principles of Justice and Political Economy, 11 "The Mirage of Social Justice". Chicago: The University of Chicago Press 1976

Albert O. Hirschmann, Models of Reformmongering. Quarterly Journal of Economics, S. 236-257, 1963

Israel M. Kirzner, "Comment: X-Inefficiency, Error and the Scope for Entrepeneurship". In: $\underline{\text { Rizzo, }}$ (ed.) 1979, pp 140-152

Israel M. Kirzner, Wettbewerb und Unternehmertum. Tübingen: Mohr/Siebeck 1978

Frank H. Knight, Risk, Uncertainty, and Profit. Chicago: University of Chicago Press 1971 (orig: Houghton 1921)

Wilhelm Krelle, Preistheorie I, II. Tübingen: Mohr/Siebeck 1976.

Friedrich Kübler, Walter Schmidt, Spiros Simitis, Mitbestimmung als gesetzgebungspolitische Aufgabe: Zur Verfassungsmäßigkeit des Mitbestimmungsgesetzes 1976. Baden Baden: Nomos 1978 ("Frankfurter Gutachten")

Ludwig M. Lachmann, "The Flow of Legislation and the Permanence of the Legal Order." Zur Verfassung der Freiheit. Festgabe für Friedrich August von Hayek zur Vollendung seines 80. Lebensjahres. Ordo 30, 1977, S. 69-78

William Lazonick, "Industrial Relations and Technical Change: The Case of the Self-Acting Mule". Cambridge Journal of Economics 3.3, Sept. 1979

William Lazonick, "Managers, Entrepeneurs, and Choice of Technique: Rings and Mules in Lancashire". Harvard Institute of Economic Research Discussion Paper 726 Oct. 1979

Harvey Leibenstein, "Entrepeneurship and Development". American Economic Review, Papers \& Proceedings, 58.2, 1968, 72-83

Harvey Leibenstein, "The General X-Efficiency Paradigm and the Role of the Entrepeneur". in:

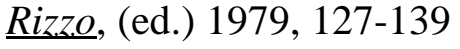

Siegfried Lenz, Lehmanns Erzählungen oder So schön war mein Markt Hamburg: Hoffmann und Camper, 1964 (= München: deutscher taschenbuchverlag)

Roland N. Mackean, "The Unseen Hand in Government”. American Economic Review 55.3, 1965, pp 496-506

James Edward Meade, "The Theory of Labour Managed Firms and of Profit Sharing." Economic 
Journal 82, 1972, S. 402-428

Walter Meyer, Die finanzsoziologischen Ansichten der Paretoschule in Italien. Bonner Diss. 1953

Hans G. Monissen, Economics and the Public Purpose: Some Discussion Points Related to Chapter Three of John Kenneth Galbraith's Homonymous Book, Schweizerische Zeitschrift für Volkswirtschaft und Statistik, 111, 1975, S. 317-336

Robert Nozick, Anarchy, State, and Utopia. New York: Basic Books 1974

Mancur Olson jr., The Logic of Collective Action. Cambridge: Harvard University Press 1965. dt.: Die Logik des kollektiven Handelns. Tübingen: Mohr/Siebeck 1968.

Mancur Olson, The Political Economy of Comparative Growth Rates. Mimeograph University of Maryland, 1978.

Vilfredo Pareto, Manual of Political Economy. New York: Kelley 1971.

Vilfredo Pareto, The Mind and Society. New York: Harcourt/Brace 1935

J. Pierstorff, "Unternehmer und Unternehmergewinn". Handwörterbuch der Staatswissenschaften $\underline{8}, 1911(3)$, pp 95-105.

Werner W. Pommerehne \& Friedrich Schneider, "Ist der Trittbrettfahrer so bedeutend? Eine experimentelle Untersuchung". Institut für empirische Wirtschaftsforschung der Universität Zürich. Diskussionspapier 79-o4 1979.

Theodor Pütz, Das Bild des Unternehmers in der Nationalökonomie: Versuch einer aufbauenden Kritik. Jena: Fischer 1935

Fritz Redlich, The German Military Enterpriser and his Work Force: A Study in European Economic and Social History. Wiesbaden 1964/65

Fritz Redlich, Der Unternehmer: Wirtschafts- und Sozialgeschichtliche Studien. Göttingen: Vandenhoeck \& Ruprecht 1964.

Fritz Redlich, Unternehmer. Handwörterbuch der Sozialwissenschaften 10, 1959, pp 486-498

Fritz Redlich, The Military Enterprise: A Neglected Area of Research. Explorations in Entrepeneurial History, 1956, pp 252-256

Mario Rizzo, “Disequilibrium and all That: An Introductory Essay”. In: Rizzo (ed.) 1979, pp 1-18

Mario Rizzo (ed.), Time, Uncertainty, and Disequilibrium. Lexington: Heath 1979

Lord Lionel Robbins, "Hayek on Liberty." Economica 28, 1961, S. 66-81 (70) 
Jochen Röpke, Zur Stabilität und Evolution marktwirtschaftlicher Systeme aus klassischer Sicht. In: Streissler/Watrin (eds.), Zukunftsprobleme der sozialen Marktwirtschaft. Tübingen: Mohr/Siebeck 1980

Susan Rose-Ackermann, Inefficiency and Re-Election. Kyklos 33.2, 1980, 287-307

Hans Rühle, Hans-Joachim Veen (Hrsg.), "Wachsende Staatsausgaben. Ein internationaler Vergleich der Ursachen, Folgen und Begrenzungsmöglichkeiten”. Stuttgart: Bonn aktuell 1979.

Warren J. Samuels, Pareto on Policy. Elsevier: North Holland 1974.

Bertram Schefold, "Vom Energiesystem zum Wirtschaftsstil", in K.M. Meyer Abich, Bertram Schefold, Wie möchten wir in Zukunft leben, der harte und der sanfte Weg, München: Beck, 1981 S. $105-132$

Friedrich Schneider \& Werner W. Pommerehne, "Free Riding and Collective Action. An Experiment in Public Micro-economics". Quarterly Journal of Economics 96, 1981, S. 687 - 704

Josef Solterer, Die Grundsätze der pluralistischen Wirtschaft. Berlin: Duncker \& Humblot 1964.

James H. Soltow, "The Entrepeneur in Economic History". American Economic Review, Papers \& Proceedings, 58.2, 1968, pp 84-92.

Arthur Spiethoff, "Die allgemeine Volkswirtschaftslehre als geschichtliche Theorie: die Wirtschaftsstile", in Festgabe für Werner Sombart zur siebzichsten Wiederkehr seines Geburtstages 19. Jänner 1933, Arthur Spiethoff Herausgeber, München: Dunker \& Humblot, 1933, S. 51-84

Werner Schmidt, Der Wandel der Unternehmerfunktionen in der Bundesrepublik Deutschland unter dem Einfluß der konzertierten Aktion. Berlin: Duncker \& Humblot 1974.

Joseph Alois Schumpeter, Capitalism, Socialism and Democracy. London: Allen \& Unwin 1947 (2)

Joseph Alois Schumpeter, Theorie der wirtschaftlichen Entwicklung. Leipzig: Duncker \& Humblot 1912 (1) 1934 (4)

Joseph Alois Schumpeter, Art. "Unternehmer". Handwörterbuch der Staatswissenschaften, 1928 (4), VII, 476-487.

Joseph Alois Schumpeter, Der Unternehmer in der Volkswirtschaft von heute. in: B. Harms (Hrsg.), Strukturwandlungen der deutschen Volkswirtschaft I. Berlin: 1929, 303 ff.

Gerhard Schwödiauer, (Hrsg.), Equilibrium and Disequilibrium in Economic Theory. Proceedings of a Conference Organized by the Institute for Advanced Studies in Vienna, Austria, July 3-5 1974. Dordrecht: Reidel 1978.

Richard E. Wagner, "Economic Manipulation for Political Profit: Macro-Economic Consequences 
and Constitutional Implications”. Kyklos, 30.3, 1977, 395-410

Richard E. Wagner, "Pressure Groups and Political Entrepreneurs: A Review Article". Public

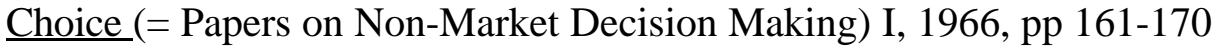

Richard E. Wagner, "Economic Manipulation for Political Profit". Kyklos 30, 1977, pp. 395-410

Elliot Roy Weintraub, General Equilibrium Theory. London: Macmillan 1974.

Elliot Roy Weintraub, Microfoundations: The Compatibility of Microeconomics and Macroeconomics. Cambridge: University Press 1979.

Max Weber, "Die Objektivität sozialpolitischer und social-wissenschaftlicher Erkenntnis". Archiv für Sozialwissenschaften und Sozialpolitik 1904

Karl Georg Zinn, "Indeterminismus und Modell: Zur Deutung der pluralistischen Wirtschaft". ORDO 18, 1967, pp 441-445. 